\title{
Long non-coding RNA HCG18 facilitates the progression of laryngeal and hypopharyngeal squamous cell carcinoma by upregulating FGFR1 via miR-133b
}

\author{
HONGBIN PENG ${ }^{1}$ and PINGJIANG GE ${ }^{2}$ \\ ${ }^{1}$ Department of Otorhinolaryngology Head and Neck Surgery, Zhongshan Hospital of \\ Traditional Chinese Medicine Affiliated to Guangzhou University of Chinese Medicine, \\ Zhongshan, Guangdong 528400; ${ }^{2}$ Department of Otorhinolaryngology Head and Neck Surgery, \\ Guangdong Provincial People's Hospital, Guangzhou, Guangdong 510000, P.R. China
}

Received April 25, 2021; Accepted September 9, 2021

DOI: $10.3892 / \mathrm{mmr} .2021 .12562$

\begin{abstract}
It has been reported that long non-coding RNA HLA complex group 18 (HCG18) is involved in the progression of cancer, acting as an oncogenic gene. The aim of the present study was to investigate the mechanism underlying the action of HCG18 in laryngeal and hypopharyngeal squamous cell carcinoma (LHSCC). The expression levels of HCG18, microRNA (miR)-133b and fibroblast growth factor receptor 1 (FGFR1) in LHSCC tissues and transfected LHSCC cells were evaluated by reverse transcription-quantitative PCR or immunohistochemistry. The viability, migration and invasion of transfected LHSCC cells were detected by Cell Counting Kit-8, wound healing and Transwell assays, respectively. The targeting relationships of HCG18, miR-133b and FGFR1 were predicted by bioinformatics analysis and confirmed using a dual-luciferase reporter assay. Moreover, the expression levels of FGFR1, phosphorylated (p)-PI3K, PI3K, p-AKT, AKT, p53, Bax and Bcl-2 in transfected LHSCC cells were measured by western blotting. It was found that the expression levels of HCG18 and FGFR1 were upregulated, but those of miR-133b were downregulated in LHSCC tissues. Short hairpin RNA (sh) HCG18 and miR-133b mimic inhibited LHSCC cell viability, while enhancing miR-133b expression. HCG18 could competitively bind with miR-133b. Moreover, the miR-133b inhibitor promoted cell viability, migration, invasion and the expression levels of Bcl-2, p-PI3K and p-AKT, but inhibited
\end{abstract}

Correspondence to: Dr Hongbin Peng, Department of Otorhinolaryngology Head and Neck Surgery, Zhongshan Hospital of Traditional Chinese Medicine Affiliated to Guangzhou University of Chinese Medicine, 3 Kangxin Road, West, Zhongshan, Guangdong 528400, P.R. China

E-mail: penhonbb_honbb@163.com

Key words: HLA complex group 18, laryngeal and hypopharyngeal squamous cell carcinoma, microRNA-133b, fibroblast growth factor receptor 1 , migration the expression levels of p53 and Bax, which were abrogated by shHCG18. miR-133b could competitively bind with FGFR1, and the miR-133b mimic decreased the expression level of FGFR1 in transfected LHSCC cells. shFGFR1 promoted the expression levels of p53 and Bax, while inhibiting viability, migration, invasion and $\mathrm{Bcl}-2, \mathrm{p}-\mathrm{PI} 3 \mathrm{~K}$ and $\mathrm{p}-\mathrm{AKT}$ expression in LHSCC cells. In conclusion, the current results indicated that HCG18 facilitated the progression of LHSCC by upregulating FGFR1 via miR-133b. The present study evaluated the mechanism with regards to the action of HCG18 in LHSCC, and these experimental results may provide novel evidence for targeted therapy of LHSCC.

\section{Introduction}

Laryngeal cancer is an aggressive malignant tumor of the head and neck, the main pathological type of which is laryngeal squamous cell carcinoma (LSCC) (1). It has been shown that there are nearly 170,000 new cases of laryngeal cancer each year worldwide, and $>90,000$ individuals die of laryngeal cancer (2). The incidence of hypopharyngeal cancer is $\sim 1 / 4$ of that of laryngeal cancer, of which laryngeal and hypopharyngeal squamous cell carcinoma (LHSCC) is one type with a poor prognosis (2), making its treatment difficult. Currently, surgical resection of the tumor is the standard treatment, while radiotherapy and chemotherapy have also shown efficacy in trials $(3,4)$. However, some patients who undergo surgery and postoperative adjuvant chemoradiotherapy may have the possibility of recurrence (5). Therefore, it is important to improve the prognosis of LHSCC by searching for new therapeutic agents and targets.

The occurrence and progression of cancer are regulated by multiple genes, and long non-coding RNAs (lncRNAs) are RNAs with a total length $>200$ nucleotides but without protein-coding ability (6). An increasing number of studies have shown that lncRNAs play key roles in the treatment and diagnosis of various cancer types (7-9). It has been reported that IncRNA HLA complex group 18 (HCG18) expression was upregulated in gastric cancer and colorectal cancer tissues, and knockdown of HCG18 expression notably decreased the 
proliferation, migration and invasion of cancer cells $(10,11)$. Moreover, HCG18 has been found to act as an oncogene in lung adenocarcinoma and promote tumor growth (12). In addition, HCG18, as an oncogenic lncRNA involved in the progression of cancer, is associated with poor prognosis in nasopharyngeal carcinoma (13). Nevertheless, its detailed biological functions and molecular mechanism in LHSCC are yet to be fully elucidated.

Recent findings have suggested that lncRNAs could be involved in the progression of cancer by regulating the expression levels of microRNAs (miRNAs/miRs) (6). miRNAs are a class of evolutionarily conserved non-coding small molecular RNAs that have the function of regulating gene expression at the translation level (14). Furthermore, existing evidence has indicated that HCG18 regulates the migration and proliferation of bladder cancer cells by regulating the expression of miR-34c-5p (15). It has also been revealed that HCG18 promotes the development of nasopharyngeal carcinoma by regulating the expression of miR-140 (13). In addition, miR-133b plays important roles in inflammation and tumors, where it has been revealed that miR-133b was aberrantly expressed in numerous tumor types, including colorectal cancer, esophageal squamous cell carcinoma and human tongue squamous cell carcinoma (16-19). However, to the best of our knowledge, the specific effects of miR-133b in LHSCC remain unknown.

Therefore, the present study aimed to examine the expression levels of HCG18 and miR-133b in LHSCC, and determine the mechanism underlying the action of HCG18 and miR-133b so as to propose a potential approach for targeted therapy of LHSCC.

\section{Materials and methods}

Ethics statement. This study was discussed and approved by the Zhongshan Hospital of Traditional Chinese Medicine Affiliated to Guangzhou University of Chinese Medicine Ethics Committee (approval no. JN2020020208), and all tissue samples were confirmed to be LHSCC. Written informed consent was obtained from the participating patients.

Patient tissue specimens. In this experiment, 50 patients (male, 27; female, 23; age, 40-65 years) with LHSCC who underwent surgical resection at Zhongshan Hospital of Traditional Chinese Medicine Affiliated to Guangzhou University of Chinese Medicine (Zhongshan, China) between February 2020 and April 2020 were selected. All patients participating in the present study met the following criteria: i) Had not received any pre-surgical therapy, including chemotherapy and radiotherapy; ii) had not been diagnosed with infectious diseases, autoimmunity-related diseases, etc. A total of 50 LHSCC tissues and 50 normal tissues adjacent to cancer tissues ( $>5 \mathrm{~cm}$ from tumor tissue) were collected from the patients.

Bioinformatics analysis. In the present study, the targeting relationships of HCG18 and miR-133b were predicted by starBase (http://starbase.sysu.edu.cn/index.php), and the targeting relationships of miR-133b and FGFR1 were predicted by TargetScanHuman (http://www.targetscan.org/vert_72/).
Cell culture. The laryngeal cancer cell line, TU212, was purchased from Tongpai Biological Technology Co., Ltd., and TU177 (cat. no. QCB1408) was obtained from Qincheng Biological Technology Co., Ltd. Both cell lines were cultured in RPMI-1640 complete medium (cat. no. PM150110B; Procell Life Science \& Technology Co., Ltd.) containing 10\% FBS (cat. no. 164210; Procell Life Science \& Technology Co., Ltd.) and $1 \%$ penicillin-streptomycin (cat. no. PB180120; Procell Life Science \& Technology Co., Ltd.), and cells were grown in a cell incubator (cat. no. BC-J160; Boxun) at $37^{\circ} \mathrm{C}$ with $5 \% \mathrm{CO}_{2}$.

Cell line transfection. In this experiment, miR-133b mimic (M; cat. no. miR10000770-1-5), miR-133b M control (MC; cat. no. miR1N0000001-1-5), miR-133b inhibitor (I; cat. no. miR20000770-1-5) and miR-133b I control (IC; cat. no. miR2N0000001-1-5) were purchased from Guangzhou RiboBio Co., Ltd. Short hairpin RNAs (shRNAs; sh) targeting HCG18 (shHCG18) or FGFR1 (shFGFR1), as well as their negative control (shNC) were synthesized from Shanghai GenePharma Co., Ltd., and used for the knockdown of HCG18 and FGFR1, respectively.

TU212 and TU177 cells were collected, the concentration of which was adjusted to $5 \times 10^{4} / \mathrm{ml}$. Then, cells were cultured in 6-well plates. When cell confluence reached $80 \%$, the two cell lines were transfected with M, MC, I, IC, shHCG18, shFGFR1 or shNC $(2,500 \mathrm{ng} /$ well $)$ for $48 \mathrm{~h}$ at $37^{\circ} \mathrm{C}$ using the Lipofectamine ${ }^{\mathrm{TM}} 3000$ Transfection Reagent (cat. no. L3000150; Invitrogen; Thermo Fisher Scientific, Inc.). Transfected cells were collected after $12 \mathrm{~h}$ and used for subsequent experiments.

Dual-luciferase reporter assay. The wild-type (WT) sequence of HCG18 (HCG18-WT; 5'-AGGCUAGGACAUUUGGAC CAAC-3'), mutant (MUT) sequence of HCG18 (HCG18-MUT; 5'-AGGAGAGGACAUUUGUCACAGC-3'), WT sequence of FGFR1 (FGFR1-WT; 5'-CCCCUCCCAGAUCUUGGACCA AC-3') and MUT sequence of FGFR1 (FGFR1-MUT; 5'-CCC CUCCCAGAUCUUGCCCGAUC-3') were constructed into dual-luciferase reporter pmirGLO vectors (Promega Corporation). TU212 and TU177 cells were collected, and miR-133b M or MC (100 ng/well) were co-transfected with HCG18 reporter vectors containing the WT or the MUT (100 ng/well) into TU212 cells for $48 \mathrm{~h}$ at $37^{\circ} \mathrm{C}$; miR-133b M or MC (100 ng/well) were also co-transfected with FGFR1 reporter vectors containing the WT or the MUT (100 ng/well) into TU177 cells for $48 \mathrm{~h}$ at $37^{\circ} \mathrm{C}$. Cell line transfection was performed using the Lipofectamine 3000 Transfection Reagent. The activity of luciferase was detected on the dual luciferase reporter system (cat. no. GM3000; Promega Corporation) with a Dual Luciferase Reporter Gene Assay kit (cat. no. RG027; Beyotime Institute of Biotechnology), and Renilla luciferase activity was used as an internal reference.

Cell Counting Kit-8 (CCK-8) assay. TU212 and TU177 cell lines in the logarithmic phase were collected and were cultured in a 96-well plate (2,000 cells/well) after adjusting the concentration. After the transfection, the viability of the transfected cells was detected using a CCK-8 assay (cat. no. C0038; Beyotime Institute of Biotechnology). After the transfected 
cells were routinely cultured for $24 \mathrm{~h}, 10 \mu \mathrm{l}$ CCK- 8 solution was added to the appropriate wells, and then the cells were cultured for another $4 \mathrm{~h}$ in a $37^{\circ} \mathrm{C}$ incubator, according to the manufacturer's instructions. Finally, the absorbance of each well was measured using a microplate reader (ELx808; BioTek Instruments, Inc.) with an excitation wavelength of $450 \mathrm{~nm}$.

Wound healing assay. The transfected TU212 and TU177 cell lines were collected and cell concentration was adjusted, following which $\sim 1 \times 10^{6}$ cells were added to each well of a 6-well plate and cultured in RPMI-1640 complete medium (containing 10\% FBS and 1\% penicillin-streptomycin). When the confluence of the cell reached $\sim 100 \%$, straight scratches were made using a sterile pipette $(200 \mu 1)$ on a 6 -well plate. Then, the cells were washed with PBS (cat. no. 10010023; Thermo Fisher Scientific, Inc.) to remove the scratched cells and serum-free medium was added to 6 -well plate. The cells were incubated at $37^{\circ} \mathrm{C}$ in an incubator for $24 \mathrm{~h}$. Next, the wound was observed and imaged using an inverted microscope (magnification, x100; DMi8; Leica Microsystems $\mathrm{GmbH}$ ) at 0 and $24 \mathrm{~h}$ after scratching. Cell migration rate $=($ scratch width at $0 \mathrm{~h}$-scratch width at $24 \mathrm{~h}$ )/scratch width at $0 \mathrm{~h}$.

Transwell assay. Matrigel (cat. no. M8370; Beijing Solarbio Science \& Technology Co., Ltd.) was thawed at $4^{\circ} \mathrm{C}$ overnight, and was then diluted with pre-cooled serum-free medium. Subsequently, $20 \mu 1$ diluted Matrigel was added to the upper chamber of Transwell (cat. no. CLS3374; Merck $\mathrm{KGaA}$ ), and incubated for $1 \mathrm{~h}$ in an incubator at $37^{\circ} \mathrm{C}$. The transfected TU212 and TU177 cells were collected and suspended in serum-free medium to adjust the concentration to $5 \times 10^{5}$ cell $/ \mathrm{ml}$. When Matrigel was gelled, $200 \mu \mathrm{l}$ cell suspension was added into each upper Transwell chamber, and then $700 \mu \mathrm{l}$ medium containing $15 \%$ FBS was added to the corresponding lower chamber. Next, the cells were incubated in an incubator at $37^{\circ} \mathrm{C}$ for $24 \mathrm{~h}$. The chamber was removed and the residual cells were wiped off with a cotton swab, after which the cells were fixed with $4 \%$ paraformaldehyde (cat. no. P6148; Sigma-Aldrich; Merck KGaA) and stained with $0.1 \%$ crystal violet (cat. no. C0775; Sigma-Aldrich; Merck $\mathrm{KGaA}$ ) for $15 \mathrm{~min}$ at room temperature. Finally, the cells were observed and counted under an inverted microscope (magnification, $\mathrm{x} 200)$.

Immunohistochemistry. After collection, the specimens of LHSCC tissues and normal tissues were fixed via immersion in $4 \%$ paraformaldehyde for $24 \mathrm{~h}$ at $4^{\circ} \mathrm{C}$. Then, the tissues specimens were routinely embedded in paraffin (cat. no. P3558; Sigma-Aldrich; Merck KGaA) and then sectioned (thickness, $4 \mu \mathrm{m}$ ) using a paraffin slicer (cat. no. E0972; Beyotime Institute of Biotechnology). The paraffin sections were deparaffinized with xylene (cat. no. 9990501; Thermo Fisher Scientific, Inc.) and hydrated with different concentrations of alcohol (100, 95, 90, 80 and 70\%; cat. no. E7023; Sigma-Aldrich; Merck KGaA). The blocking solution was prepared using Triton X-100 (cat. no. P1080; Beyotime Institute of Biotechnology) and $\mathrm{H}_{2} \mathrm{O}_{2}$ (cat. no. H112517; Shanghai Aladdin Biochemical Technology Co., Ltd.). The paraffin sections were immersed in blocking solution for $30 \mathrm{~min}$ at room temperature in the dark, and then in $10 \%$ normal goat serum (cat. no. SL038;
Beijing Solarbio Science \& Technology Co., Ltd.) for $20 \mathrm{~min}$ at $37^{\circ} \mathrm{C}$. Next, sections were incubated firstly with anti-FGFR1 antibody (cat. no. ab10646; Abcam; 1:200) at $4^{\circ} \mathrm{C}$ for $12 \mathrm{~h}$ and then with horseradish peroxidase-labeled secondary antibody (rabbit IgG; cat. no. ab205718; Abcam; 1:2,000) at $37^{\circ} \mathrm{C}$ for $30 \mathrm{~min}$. The sections were washed with PBS, treated with DAB (cat. no. DA1015; Beijing Solarbio Science \& Technology Co., Ltd.) at room temperature for $10 \mathrm{~min}$, and counterstained with Mayer's hematoxylin solution (cat. no. G1080; Beijing Solarbio Science \& Technology Co., Ltd.) for $2 \mathrm{~min}$ at room temperature. Then, the sections were treated with different concentrations of alcohol $(50 \%$ for $2 \mathrm{~min} ; 70 \%$ for $2 \mathrm{~min}$; $95 \%$ for $1 \mathrm{~min}$; $100 \%$ for $1 \mathrm{~min}$ ) at room temperature, rinsed using xylene and mounted with Neutral balsam (cat. no. G8590; Beijing Solarbio Science \& Technology Co., Ltd.). Finally, the sections were imaged (magnification, x200) under an inverted microscope. Immunohistochemistry revealed that FGFR1 was stained brownish-yellow. Briefly, the mean gray value (staining intensity) of positive cells was analyzed using ImageJ software (version 1.50i; National Institutes of Health), and the cells were then classified as high-positive $(+++)$, positive $(++)$, low-positive $(+)$ and negative $(0)$ according to the degree of staining. Meanwhile, the positive area (staining area) of the sections was determined using ImageJ software, and then the percentage of cells with different grades of staining in the total staining area was calculated.

Reverse transcription-quantitative PCR (RT-qPCR). The collected LHSCC tissues were minced and transferred into centrifuge tubes, to which the transfected LHSCC cells were transferred as well. Then, the extraction of total RNA from cells and tissue samples was performed using TRIzol ${ }^{\circledR}$ reagent (cat. no. 15596018; Thermo Fisher Scientific, Inc.) according to the manufacturer's instructions. The concentration and purity of the RNA were assessed by measuring the absorbance values of the RNA solutions using a spectrophotometer (ND-ONEC-W; Thermo Fisher Scientific, Inc.). The RT-PCR reaction system was configured using the One Step RT-PCR SuperMix kit (cat. no. T2240; Beijing Solarbio Science \& Technology Co., Ltd.). The RT-PCR reaction system was performed and the expressions of genes were measured on the RT-PCR system (Bio-Rad iQ5; Bio-Rad Laboratories, Inc.) under the conditions: $50^{\circ} \mathrm{C}, 20 \mathrm{~min}, 1$ cycle; $95^{\circ} \mathrm{C}, 3 \mathrm{~min}$, 1 cycle; $95^{\circ} \mathrm{C}, 10 \mathrm{sec}, 60^{\circ} \mathrm{C}, 15 \mathrm{sec}, 72^{\circ} \mathrm{C}, 30 \mathrm{sec}, 40$ cycles; and $72^{\circ} \mathrm{C}, 5 \mathrm{~min}, 1$ cycle. GAPDH and U6 were used as reference genes, and sequences of all primers used are shown in Table I. The results of RT-qPCR were analyzed using the $2^{-\Delta \Delta \mathrm{Cq}}$ method (12)

Western blotting. The transfected TU212 and TU177 cell lines were collected in centrifuge tubes, and the cells were washed twice with precooled PBS (each time for $2 \mathrm{~min}$ ), and then the appropriate amount of RIPA lysis buffer (cat. no. P0013C; Beyotime Institute of Biotechnology) was added to the centrifuge tubes to extract total protein from the LHSCC cells, after which the concentration of the total protein was measured using BCA protein kit (cat. no. P0010; Beyotime Institute of Biotechnology). The SDS-PAGE gel $(6,8$ or $10 \%)$ was prepared using an SDS-PAGE Gel Quick Preparation kit (cat. no. P0012AC; Beyotime Institute of Biotechnology), and 
Table I. All primers used in reverse transcription-quantitative PCR experiments.

\begin{tabular}{lll}
\hline Gene & \multicolumn{1}{c}{ Forward sequence $\left(5^{\prime}-3^{\prime}\right)$} & Reverse sequence $\left(5^{\prime}-3^{\prime}\right)$ \\
\hline miR-133b & AAACCTGGCGGCCACGCTAC & GACCGTGGTCCACTGCAGGC \\
HCG18 & TTGGCTTCAGTCCTGTTCATCAG & ACCTTGCACACTGTCTCTTG \\
FGFR1 & CCCGTAGCTCCATATTGGACA & TTTGCCATTTTTCAACCAGCG \\
GAPDH & CTCGCTTCGGCAGCACATATACT & ACGCTTCACGAATTTGCGTGTC \\
\hline
\end{tabular}

miR, microRNA; HCG18, HLA complex group 18; FGFR1, fibroblast growth factor receptor 1.

Table II. All antibody information for those used in western blotting assay.

\begin{tabular}{|c|c|c|c|c|}
\hline ID & Cat. no. & Company & $\begin{array}{c}\text { Molecular } \\
\text { weight (kDa) }\end{array}$ & Dilution ratio \\
\hline p-PI3K & ab182651 & Abcam & 84 & $1: 1,000$ \\
\hline PI3K & 4249 & CST & 110 & $1: 1,000$ \\
\hline $\mathrm{p}-\mathrm{AKT}$ & 4060 & CST & 60 & $1: 2,000$ \\
\hline $\mathrm{AKT}$ & 4685 & CST & 60 & $1: 1,000$ \\
\hline p53 & 2527 & CST & 53 & $1: 1,000$ \\
\hline $\operatorname{Bax}$ & 5023 & CST & 20 & $1: 1,000$ \\
\hline $\mathrm{Bcl}-2$ & 3498 & CST & 26 & $1: 1,000$ \\
\hline FGFR1 & 9740 & CST & 120 & $1: 1,000$ \\
\hline Rabbit IgG & $a b 205718$ & Abcam & N/A & $1: 5,000$ \\
\hline GAPDH & 5174 & CST & 36 & $1: 1,000$ \\
\hline
\end{tabular}

CST, Cell Signaling Technology, Inc.; p-, phosphorylated; FGFR1, fibroblast growth factor receptor 1; N/A, not applicable.

an appropriate amount $(20 \mu \mathrm{l}, 2 \mu \mathrm{g} / \mu \mathrm{l})$ of protein sample was added to the sample well before electrophoresis. After the completion of electrophoresis, the separated protein was transferred to a PVDF membrane (cat. no. 88518; Thermo Fisher Scientific, Inc.), which was then immersed in blocking solution containing 5\% skimmed milk at room temperature for $1 \mathrm{~h}$. Subsequently, the PVDF membrane was washed in $1 \mathrm{X}$ TBS-0.1\% Tween-20 (TBST) solution (cat. no. ST673; Beyotime Institute of Biotechnology) three times (each time for $10 \mathrm{~min}$ ), and then immersed in diluted primary antibody solution at $4^{\circ} \mathrm{C}$ overnight after the dilution of the primary antibody with TBST to the appropriate concentration. The following day, the PVDF membrane was soaked in diluted secondary antibody solution at $37^{\circ} \mathrm{C}$ for $1.5 \mathrm{~h}$ after being washed with TBST solution. Then, the PVDF membrane was washed with TBST solution again, and the Pierce ${ }^{\mathrm{TM}}$ ECL Western Blotting substrate (cat. no. 32106; Thermo Fisher Scientific, Inc.) was used for visualization following the collection of protein bands. The signals were finally read using a ChemiDoc XRS+ system (Bio-Rad Laboratories, Inc.). All the expressions of proteins were normalized against GAPDH, and the information for the antibodies used is listed in Table II.

Statistical analysis. Statistical analysis was performed using GraphPad Prism 8.0 (GraphPad Software, Inc.). Measurement data are presented as the mean $\pm \mathrm{SD}$ and were indicative of three experiments independently. An independent sample t-test was used for comparison between two groups (paired sample t-test was used for comparison between cancer tissue and normal tissues), and one-way anova was performed for comparison between multiple groups followed by Tukey's post hoc test. $\mathrm{P}<0.05$ was considered to indicate a statistically significant difference.

\section{Results}

HCG18 expression is increased and miR-133b expression is decreased in LHSCC tissues. To confirm the roles of HCG18 and miR-133b in LHSCC, the expression levels of miR-133b and HCG18 in LHSCC tissues and normal tissues were examined. It was found that the expression level of miR-133b was downregulated in LHSCC tissues in comparison with adjacent normal tissue $(\mathrm{P}<0.001$; Fig. 1A). However, the expression level of HCG18 was upregulated in LHSCC tissues compared with adjacent normal tissue $(\mathrm{P}<0.001$; Fig. 1B).

shHCG18 and miR-133b M inhibit LHSCC cell viability, while enhancing miR-133b expression. As shown in Fig. $1 C$ and D, the transfection efficiency was examined via RT-qPCR, which demonstrated that shHCG18 inhibited the expression of HCG18 in comparison with the shNC group $(\mathrm{P}<0.001)$. Moreover, the miR-133b M promoted miR-133b expression $(\mathrm{P}<0.001)$, while 
A

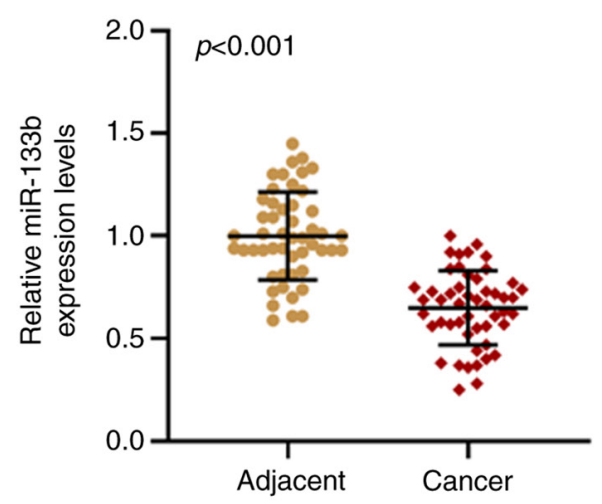

C
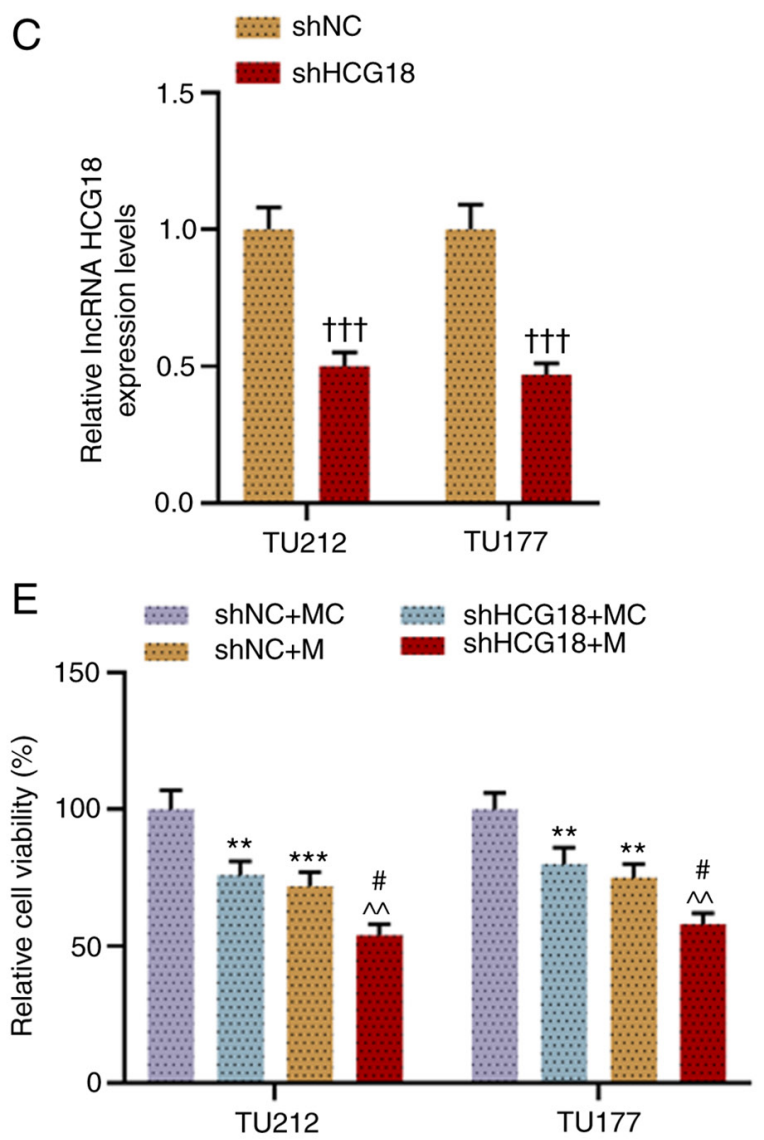

B
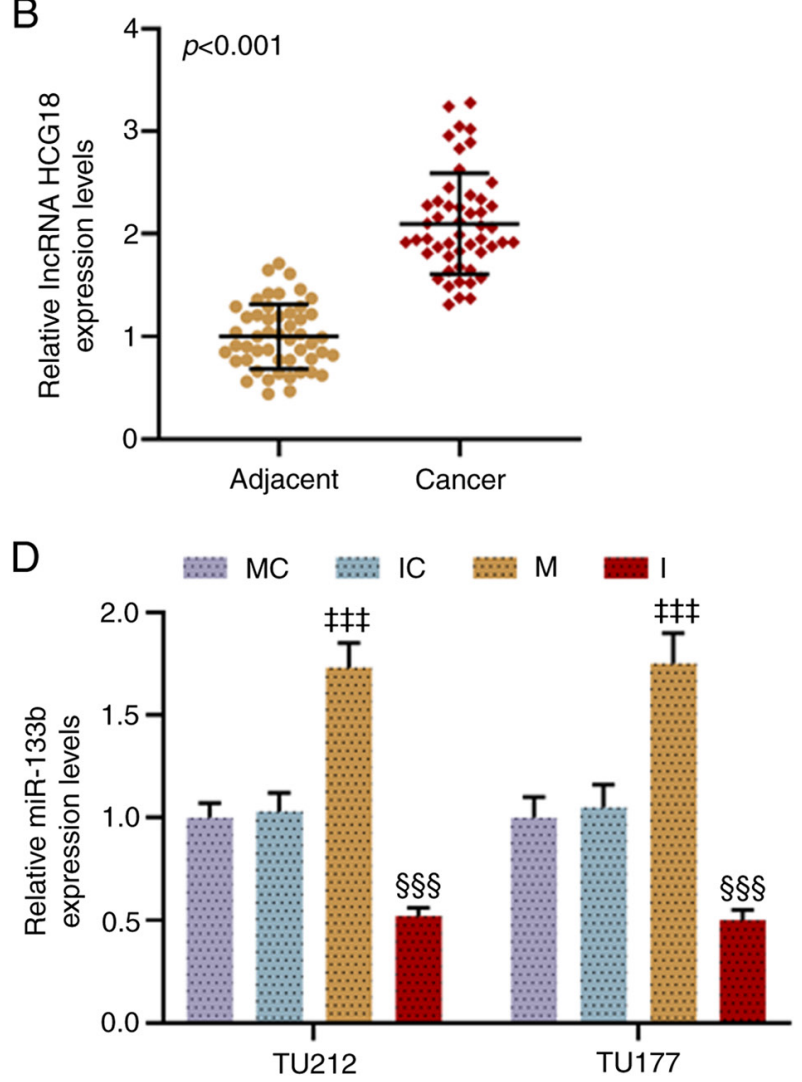

$\mathrm{F}$

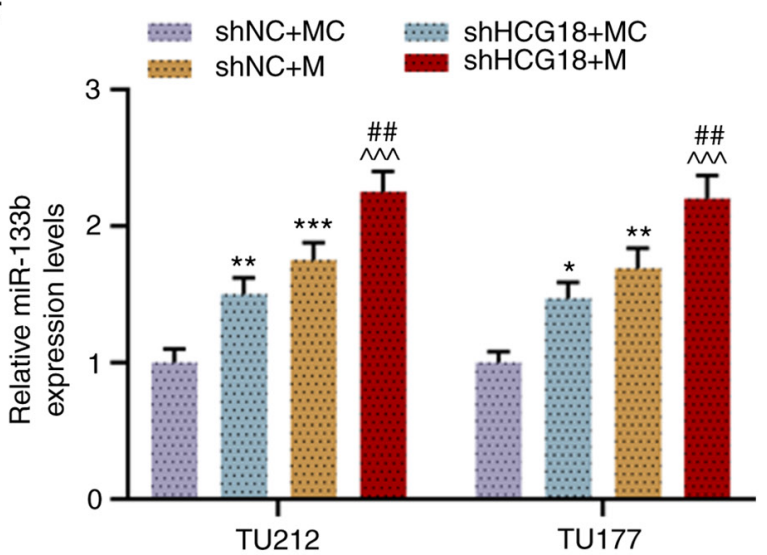

Figure 1. HCG18 expression is increased and that of miR-133b is decreased in LHSCC tissues, and shHCG18 and miR-133b M inhibit LHSCC cell activity while enhancing miR-133b expression. (A) Expression level of miR-133b in LHSCC tissues was examined via RT-qPCR, and U6 was used as a reference gene. Expression level of HCG18 in (B) LHSCC tissues and (C) transfected LHSCC cells was examined via RT-qPCR, and GAPDH was used as a reference gene. (D) Expression level of miR-133b in transfected LHSCC cells was examined via RT-qPCR, and U6 was used as a reference gene. (E) Viability of transfected TU212 and TU177 cell lines was evaluated using a Cell Counting Kit-8 assay. (F) Expression of miR-133b in transfected TU212 and TU177 cells was examined

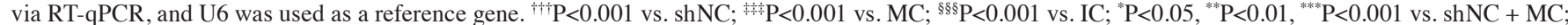
${ }^{\wedge} \mathrm{P}<0.01,{ }^{\wedge \wedge} \mathrm{P}<0.001$ vs. shHCG18 + MC; ${ }^{\#} \mathrm{P}<0.05,{ }^{\# \#} \mathrm{P}<0.01$ vs. shHCG18 + M. LHSCC, laryngeal and hypopharyngeal squamous cell carcinoma; RT-qPCR, reverse transcription-quantitative PCR; M, mimic; MC, mimic control; IC, inhibitor control; I, inhibitor; miR, microRNA; sh, short hairpin RNA; shNC, short hairpin negative control; lncRNA, long non-coding RNA; HCG18, HLA complex group 18.

the miR-133b I knocked down its expression, compared with their respective control groups $(\mathrm{P}<0.001)$. In addition, it was found that HCG18 knockdown and miR-133b overexpression inhibited the viability of LHSCC cell, while enhancing the expression level of miR-133b, when compared with the shNC + MC group $(\mathrm{P}<0.05$; Fig. $1 \mathrm{E}$ and $\mathrm{F})$. Moreover, when miR-133b M and shHCG18 were co-transfected, the inhibitory effects on cell viability and the promotive effects on the expression of miR-133b were notably enhanced as compared with the shHCG18 + MC group and shNC + M group $(\mathrm{P}<0.05$; Fig. 1E and F).

HCG18 can competitively bind with miR-133b in LHSCC cells, and miR-133b I promoted cell viability, migration and invasion, which is reversed by shHCG18. The targeting relationship of miR-133b and HCG18 was predicted using bioinformatics analysis (Fig. 2A). Next, a dual-luciferase reporter assay was performed to confirm the relationship, 

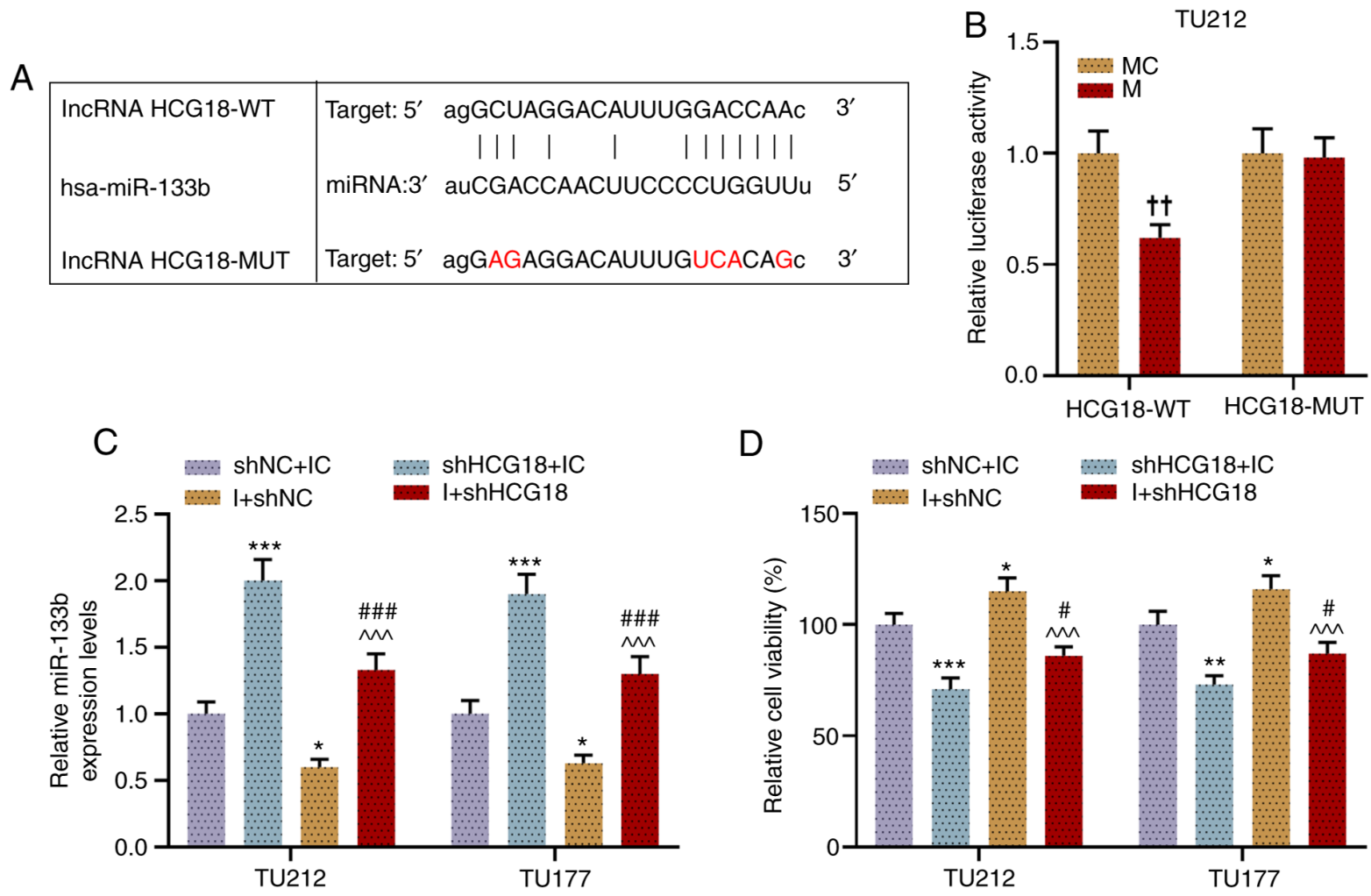

Figure 2. HCG18 can competitively bind with miR-133b in laryngeal and hypopharyngeal squamous cell cells, and miR-133b I promotes cell viability, which is reversed by shHCG18. (A) Binding sites of miR-133b and HCG18 were predicted using starBase. (B) Binding sites of miR-133b and HCG18 were validated using a dual-luciferase reporter assay. (C) Expression level of miR-133b in transfected TU212 and TU177 cells was examined via reverse transcription-quantitative PCR, and U6 was used as a reference gene. (D) Viability of transfected TU212 and TU177 cell lines was evaluated using a Cell Counting Kit-8. ${ }^{\dagger} \mathrm{P}<0.01$ vs. $\mathrm{MC} ;{ }^{*} \mathrm{P}<0.05,{ }^{* *} \mathrm{P}<0.01,{ }^{* * *} \mathrm{P}<0.001$ vs. shNC + IC; ${ }^{\wedge \wedge} \mathrm{P}<0.001$ vs. shHCG18 + IC; ${ }^{\#} \mathrm{P}<0.05,{ }^{\# \#} \mathrm{P}<0.001$ vs. shHCG18 + I. M, mimic; MC, mimic control; IC, inhibitor control; I, inhibitor; miR, microRNA; sh, short hairpin RNA; shNC, short hairpin negative control; lncRNA, long non-coding RNA; HCG18, HLA complex group 18; WT, wild-type; MUT, mutant.

from which miR-133b was successfully determined as the candidate miRNA that could competitively bind with HCG18. For instance, when TU212 cells were co-transfected with HCG18-WT and miR-133b M, the luciferase activity of the cells was lower than that of cells co-transfected with HCG18-WT and miR-133b MC, while there was no notable difference in the luciferase activity of each group of cells when TU212 cells were co-transfected with HCG18-MUT and miR-133b M or MC ( $\mathrm{P}<0.01$; Fig. 2B). Moreover, it was found that shHCG18 increased miR-133b expression, while the miR-133b I decreased this, as compared with the shNC + IC group $(\mathrm{P}<0.05)$. After the co-transfection of shHCG18 and miR-133b I into LHSCC cells, shHCG18 reversed the inhibitory effect of miR-133b I on the expression level of miR-133b ( $\mathrm{P}<0.001$; Fig. 2C). Additionally, the viability (Fig. 2D), migration (Fig. 3A and B) and invasion (Fig. 3C and D) of LHSCC cells after transfection were evaluated, and results suggested that shHCG18 decreased the viability, migration and invasion of LHSCC cells, while miR-133b I increased cell viability, migration and invasion as compared with the shNC + IC group $(\mathrm{P}<0.05)$. It was found that shHCG18 counteracted the promoting effect of the miR-133b I on the viability, migration and invasion of transfected LHSCC cells in comparison with the shHCG18 + IC group and I +shNC group $(\mathrm{P}<0.05)$.

miR-133b I promotes the expression levels of Bcl-2, $p$-PI3K and $p-A K T$, yet inhibits the expression levels of p53 and
Bax in LHSCC cells, which are reversed by shHCG18. Subsequently, the expression levels of p-PI3K, PI3K, p-AKT, $\mathrm{AKT}, \mathrm{p} 53$, Bax and $\mathrm{Bcl}-2$, and the ratios of $\mathrm{p}-\mathrm{PI} 3 \mathrm{~K} / \mathrm{PI} 3 \mathrm{~K}$ and p-AKT/AJT in transfected TU212 (Fig. 4A-E) and TU177 cells (Fig. 4F-J) were examined. It was found that the miR-133b I promoted Bcl-2 expression and the ratios of $\mathrm{p}-\mathrm{PI} 3 \mathrm{~K} / \mathrm{PI} 3 \mathrm{~K}$ and p-AKT/AKT, yet suppressed the expression levels of p53 and Bax compared with the shNC + IC group, while knockdown of HCG18 had the opposite effects in transfected LHSCC cells $(\mathrm{P}<0.05)$. Moreover, shHCG18 reversed the effect of the miR-133b I on the expression levels of p-PI3K, p-AKT, p53, Bax and Bcl-2 in transfected LHSCC cells, when compared with the shHCG18 + IC group and I + shNC group $(\mathrm{P}<0.05)$.

FGFR1 is increased and can competitively bind with miR-133b in LHSCC cells. The expression level of FGFR1 in LHSCC tissues was examined via RT-qPCR (Fig. 5A). The results demonstrated that FGFR1 expression was significantly higher in LHSCC tissues compared with in adjacent normal tissue $(\mathrm{P}<0.001)$. Also, the level of FGFR1 was examined using immunohistochemistry. Similarly, it was demonstrated that FGFR1 expression was significantly higher in LHSCC tissues compared with that in adjacent normal tissue (Fig. 5B and C). Moreover, it was observed that shFGFR1 notably decreased FGFR1 expression in comparison with the shNC group ( $\mathrm{P}<0.05$; Fig. 5D-F).

Next, the current study successfully predicted (Fig. 5G) and determined (Fig. 5H) the targeting relationship of 
A
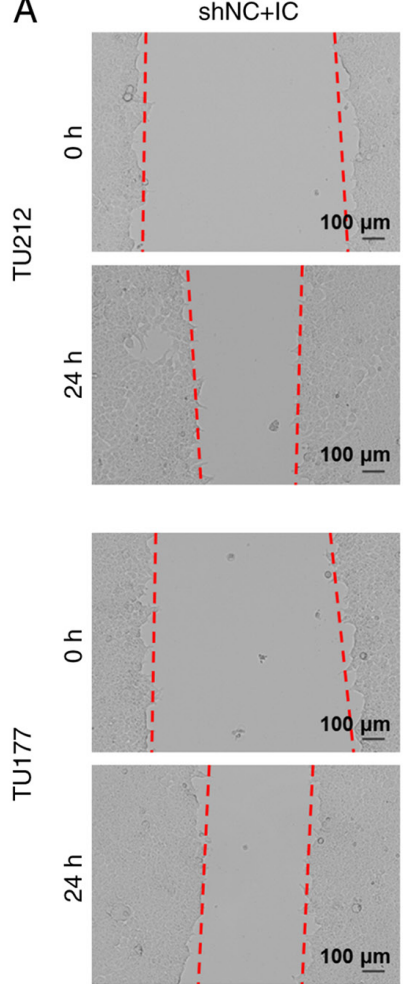

B

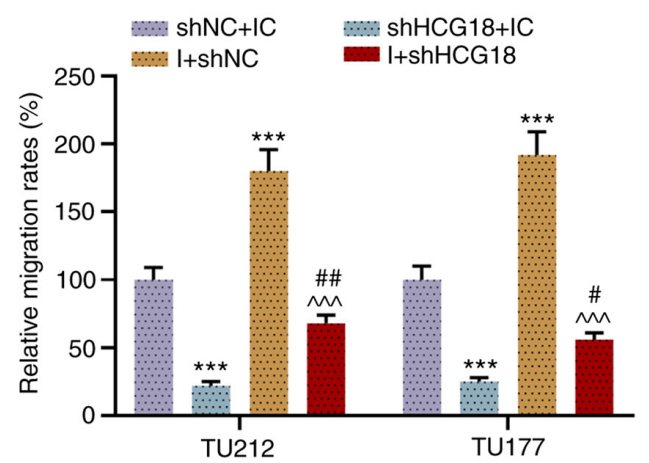

D
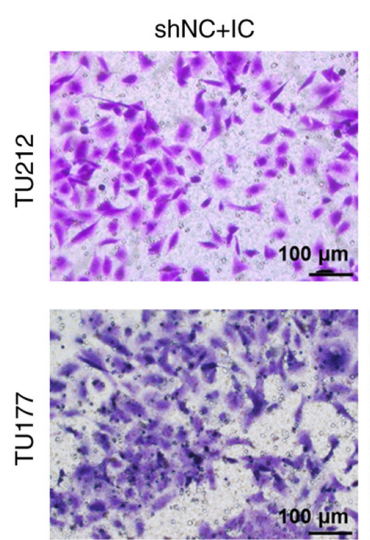
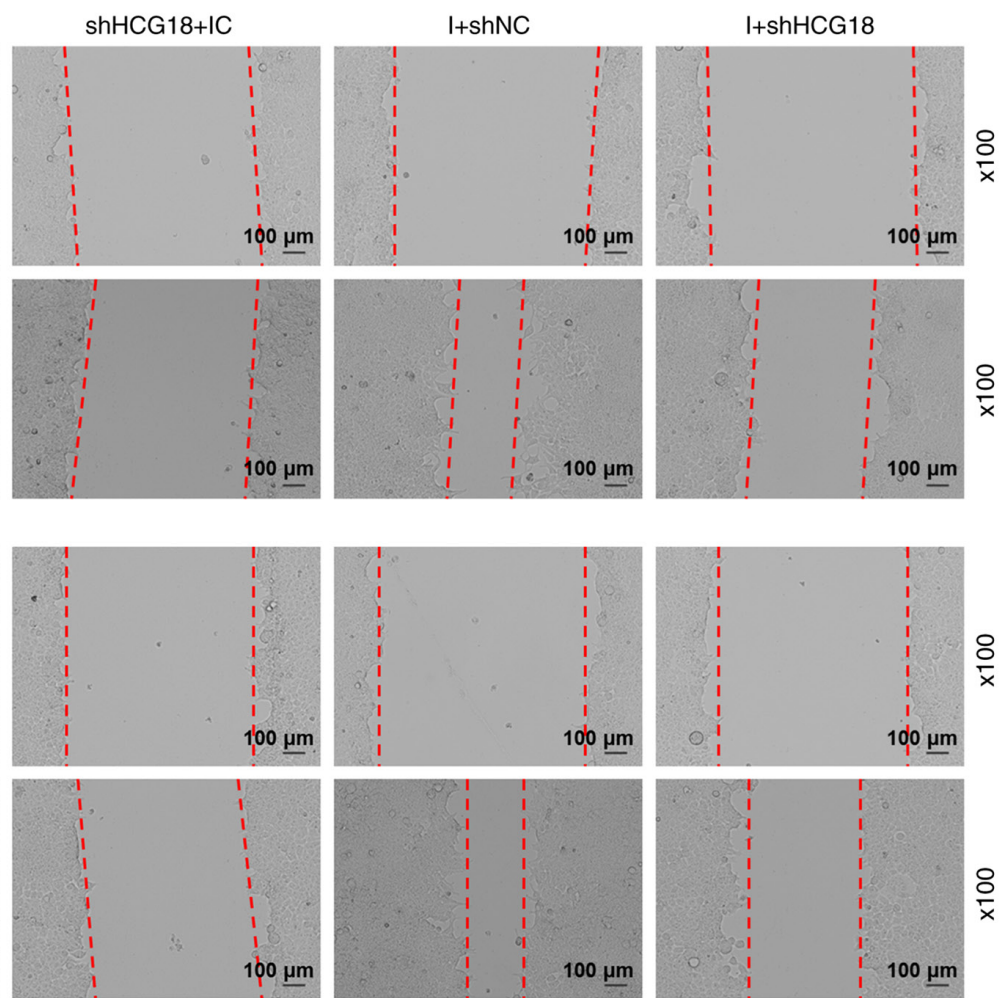

C
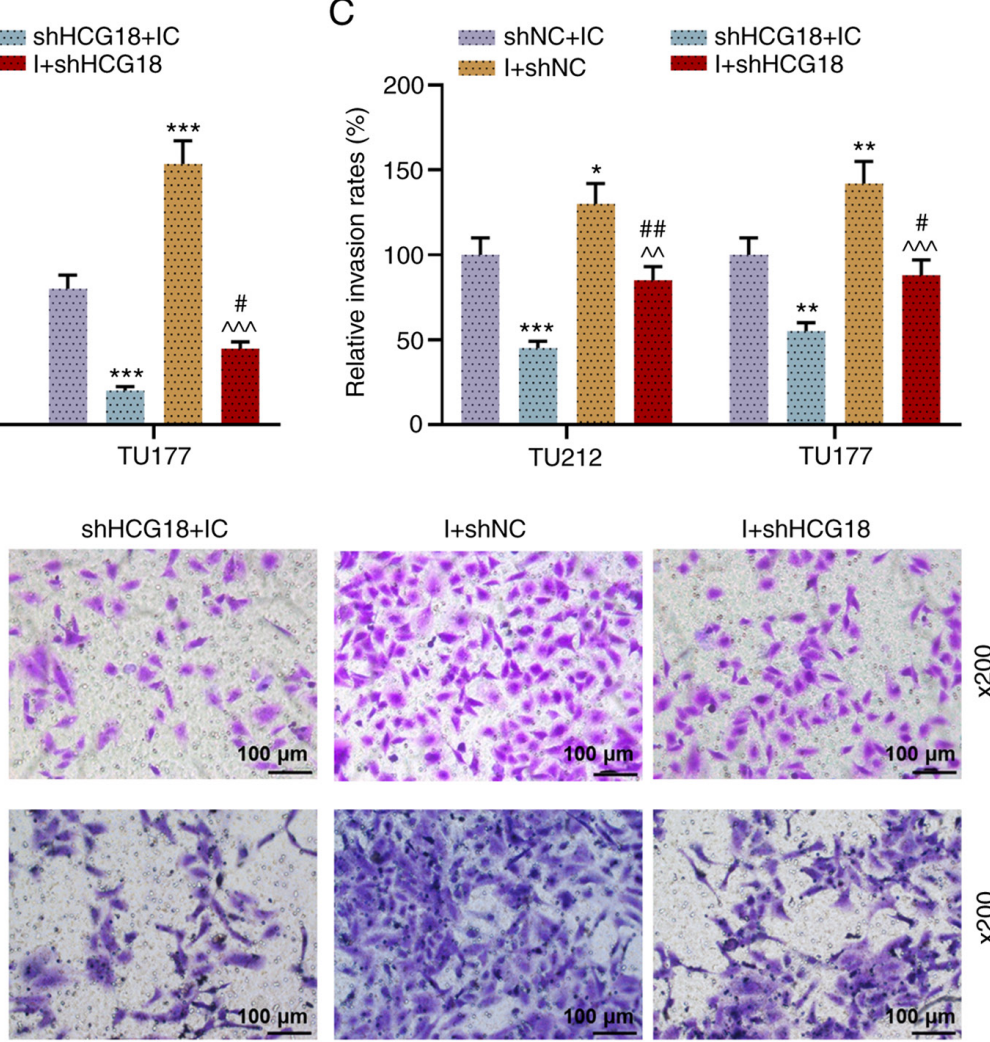

Figure 3. miR-133b I promotes cell migration and invasion, which is abrogated by shHCG18. (A and B) TU212 and TU177 cell migration after transfection was examined using a wound healing assay (magnification, x100). (C and D) Invasion of TU212 and TU177 cell lines after transfection was examined using a Transwell assay (magnification, x200). ${ }^{*} \mathrm{P}<0.05,{ }^{* *} \mathrm{P}<0.01,{ }^{* * *} \mathrm{P}<0.001$ vs. shNC $+\mathrm{IC} ;{ }^{\wedge} \mathrm{P}<0.01,{ }^{\wedge \wedge} \mathrm{P}<0.001$ vs. shHCG18 $+\mathrm{IC} ;{ }^{\#} \mathrm{P}<0.05,{ }^{\# \#} \mathrm{P}<0.01$ vs. shHCG18 + I. M, mimic; MC, mimic control; IC, inhibitor control; I, inhibitor; miR, microRNA; sh, short hairpin RNA; shNC, short hairpin negative control; lncRNA, long non-coding RNA; HCG18, HLA complex group 18.

miR-133b and FGFR1, as demonstrated in the results that when TU212 cells were co-transfected with FGFR1-WT and miR-133b M or MC, the luciferase activity after co-transfected with FGFR1-WT and miR-133b M was lower than that of cells co-transfected with FGFR1-WT and miR-133b MC, while there was no notable difference in the luciferase activity of 
TU212
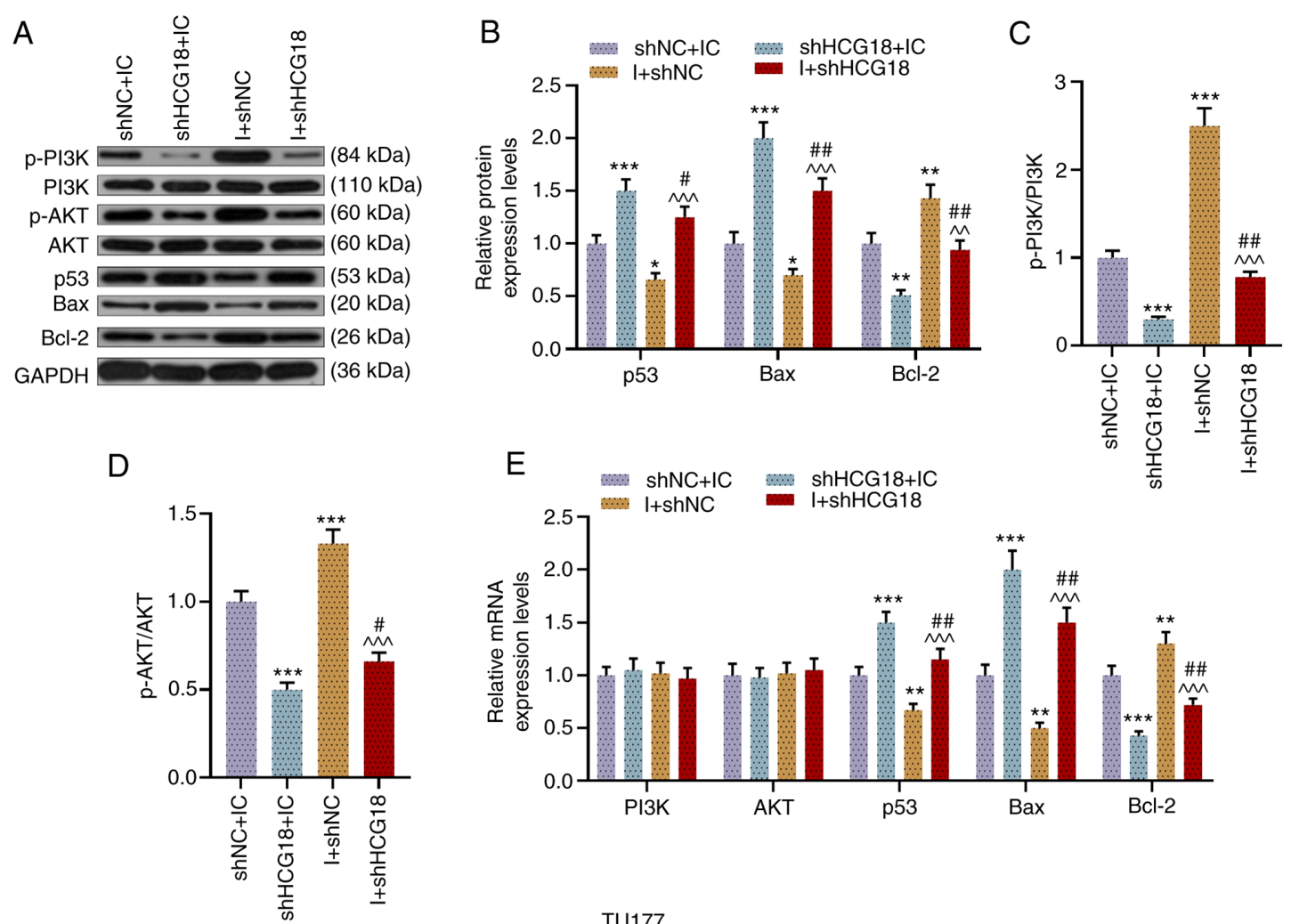

TU177
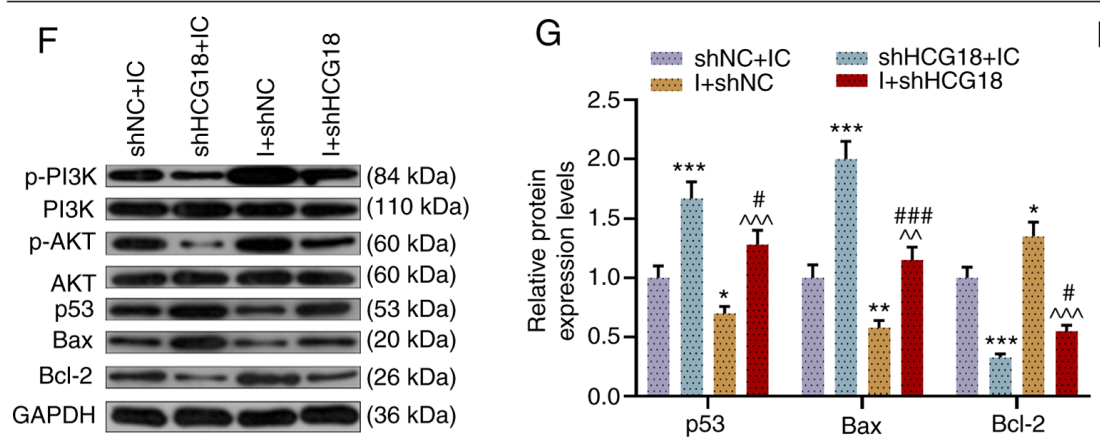

$\mathrm{H}$
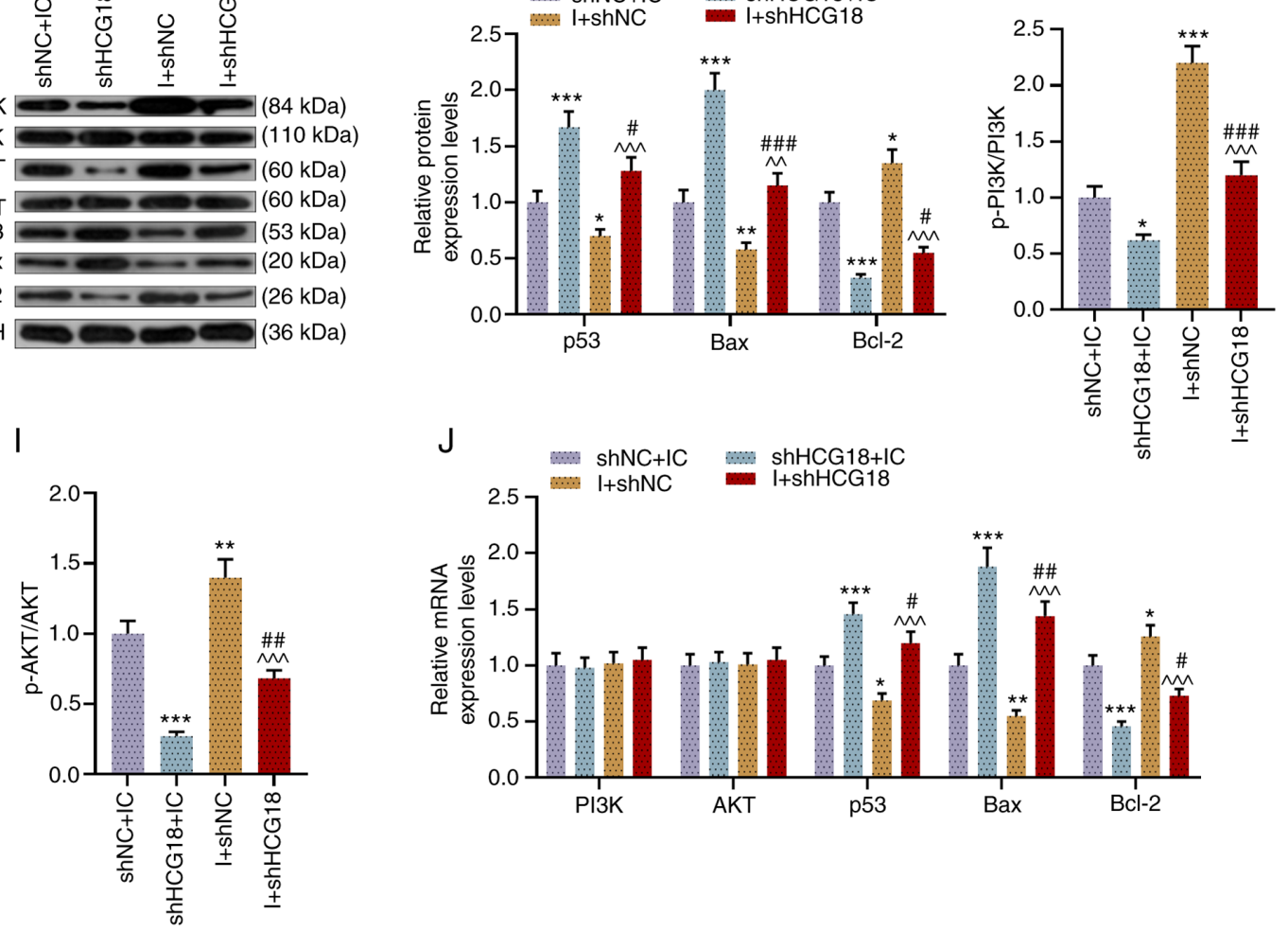

Figure 4. miR-133b I promotes the expression levels of Bcl-2, p-PI3K and p-AKT, but inhibits p53 and Bax expression in laryngeal and hypopharyngeal squamous cell carcinoma cells, while shHCG18 causes the opposite effects. (A) Protein expression levels of p-PI3K, PI3K, p-AKT, AKT, p53, Bax and Bcl-2 in transfected TU212 cells were (B) semi-quantified via western blotting, and GAPDH was used as an internal loading control. Ratios of (C) p-PI3K to PI3K and (D) p-AKT to AKT in transfected TU212 cells were analyzed on the basis of the results of western blotting assay. (E) Expression levels of PI3K, AKT, p53, Bax and Bcl-2 in transfected TU212 cells were measured via RT-qPCR, and GAPDH was used as a reference gene. (F and G) Expression levels of p-PI3K, PI3K, p-AKT, AKT, p53, Bax and Bcl-2 in transfected TU177 cells were calculated via western blotting, and GAPDH was used as an internal loading control. Ratios of (H) p-PI3K to PI3K and (I) p-AKT to AKT in transfected TU177 cells were analyzed using western blotting. (J) Expression levels of PI3K, AKT, p53, Bax and Bcl-2 in transfected TU177 cells were determined via RT-qPCR, and GAPDH was used as a reference gene. ${ }^{*} \mathrm{P}<0.05,{ }^{* * *} \mathrm{P}<0.01,{ }^{* * *} \mathrm{P}<0.001 \mathrm{vs}$. shNC $+\mathrm{IC} ;{ }^{\wedge} \mathrm{P}<0.01,{ }^{\wedge \wedge} \mathrm{P}<0.001 \mathrm{vs}$. shHCG18 + IC; ${ }^{\prime} \mathrm{P}<0.05$, ${ }^{\# \#} \mathrm{P}<0.01,{ }^{\# \# \#} \mathrm{P}<0.001$ vs. shHCG18 + I. p-, phosphorylated; RT-qPCR, reverse transcription-quantitative PCR; M, mimic; MC, mimic control; IC, inhibitor control; I, inhibitor; miR, microRNA; sh, short hairpin RNA; shNC, short hairpin negative control; lncRNA, long non-coding RNA; HCG18, HLA complex group 18. 

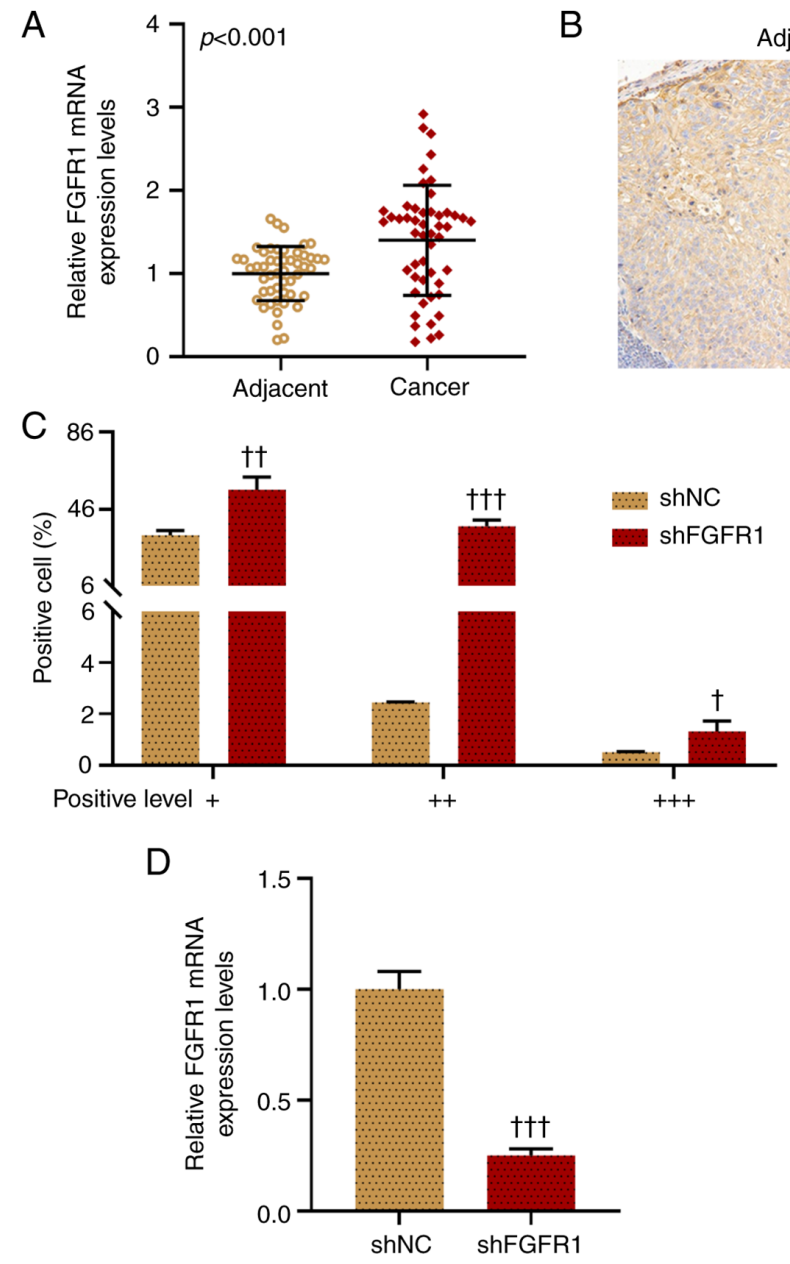

G

\begin{tabular}{|c|c|}
\hline Position $446-453$ of FGFR1 3' UTR-WT & $\begin{array}{r}5^{\prime} \quad . . C C C C U C C C A G A U C U U G G A C C A A C . . . \\
\|\|\|\| \|\end{array}$ \\
\hline hsa-miR-133b & AUCGACCAACUUCCCCUGGUUU \\
\hline Position 446-453 of FGFR1 3' UTR-MUT & $5^{\prime}, \ldots$ CCCCUCCCAGAUCUUGCCCGAUC... \\
\hline
\end{tabular}

B

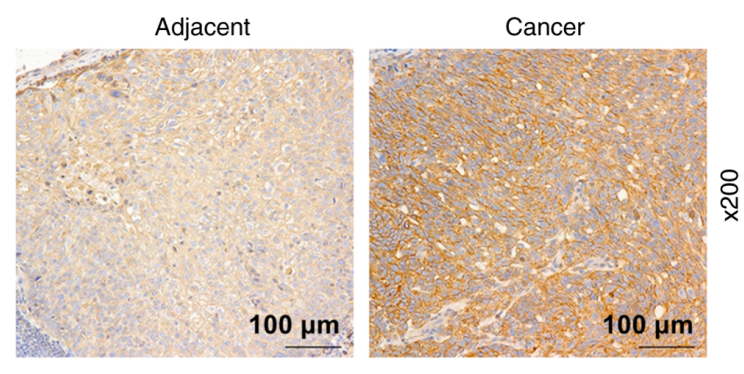

$\mathrm{E}$

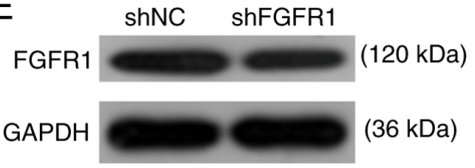

$\mathrm{F}$

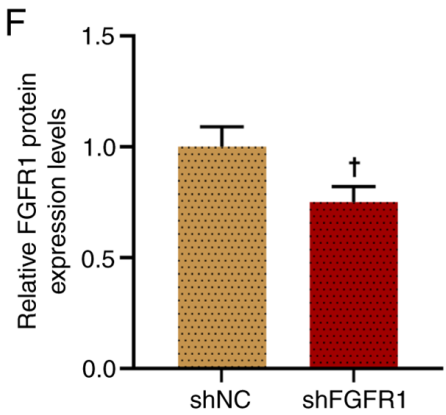

$\mathrm{H}$

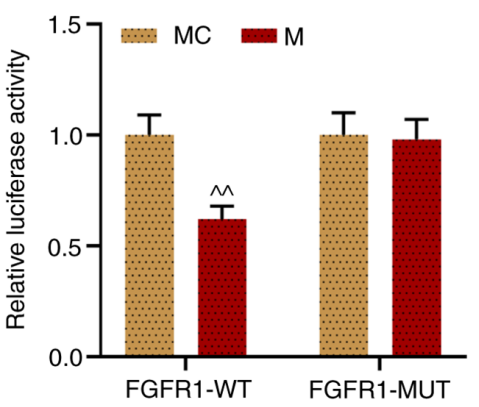

Figure 5. FGFR1 expression is increased in LHSCC, and miR-133b can bind with FGFR1 in TU212 cells. (A) Expression level of FGFR1 in LHSCC tissues was examined via RT-qPCR, and GAPDH was used as a reference gene. (B and C) Expression level of FGFR1 in LHSCC tissues was examined using immunohistochemistry. (D) Expression level of FGFR1 in transfected TU212 cells was examined via RT-qPCR, and GAPDH was used as a reference gene. (E and F) FGFR1 expression in transfected TU212 cells was examined via western blotting, and GAPDH was used as an internal loading control. The binding sites of miR-133b and FGFR1 were predicted using (G) TargetScanHuman and (H) validated using a dual-luciferase reporter assay. ${ }^{\dagger} \mathrm{P}<0.05,{ }^{\dagger} \mathrm{P}<0.01$, ${ }^{\dagger \dagger} \mathrm{P}<0.001$ vs. shNC; ${ }^{\wedge} \mathrm{P}<0.01$ vs. MC. LHSCC, laryngeal and hypopharyngeal squamous cell carcinoma; RT-qPCR, reverse transcription-quantitative PCR; M, mimic; MC, mimic control; IC, inhibitor control; I, inhibitor; miR, microRNA; sh, short hairpin RNA; shNC, short hairpin negative control; FGFR1, fibroblast growth factor receptor 1; WT, wild-type; MUT, mutant; UTR, untranslated region.

cells in each group when TU212 cells were co-transfected with FGFR1-MUT and miR-133 $\mathrm{M}$ or $\mathrm{MC}(\mathrm{P}<0.01)$. In addition, it was identified that miR-133b M significantly decreased the expression level of FGFR1 in transfected TU212 cells in comparison with the MC group ( $\mathrm{P}<0.05$; Fig. 6A-C).

shFGFRl enhanced the inhibitory effect of miR-133b $M$ on the viability, migration and invasion of LHSCC cells. Next, the present study determined the viability (Fig. 6D), migration (Fig. 6E and G), and invasion (Fig. 6F and H) of TU212 cells after transfection. These experimental results indicated that miR-133b M and shFGFR1 significantly inhibited the viability, migration and invasion of cells $(\mathrm{P}<0.01)$; however, when TU212 cells were co-transfected with miR-133b M and shFGFR1, the viability, migration and invasion of transfected TU212 cells were lower compared with those of cells in the $\mathrm{M}+\operatorname{shNC}$ and $\mathrm{MC}+\operatorname{shFGFR} 1$ groups $(\mathrm{P}<0.01)$. Thus, it was suggested that miR-133b regulated the viability, migration and invasion of cell by regulating the expression of FGFR1 in LHSCC cells.

shFGFR1 and miR-133b M promote the expression levels of $p 53$ and Bax, while inhibiting the expression levels of Bcl-2, $p-P I 3 K$ and $p$-AKT in LHSCC cells. As shown in Fig. 7A-D, shFGFR1 and miR-133b M promoted the expression levels of $\mathrm{p} 53$ and Bax, while inhibiting those of Bcl-2 and the ratios of $\mathrm{p}-\mathrm{PI} 3 \mathrm{~K} / \mathrm{PI} 3 \mathrm{~K}$ 


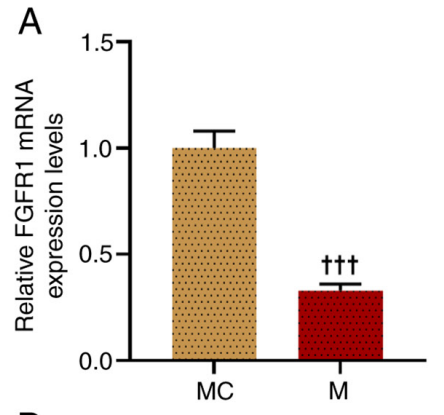

D

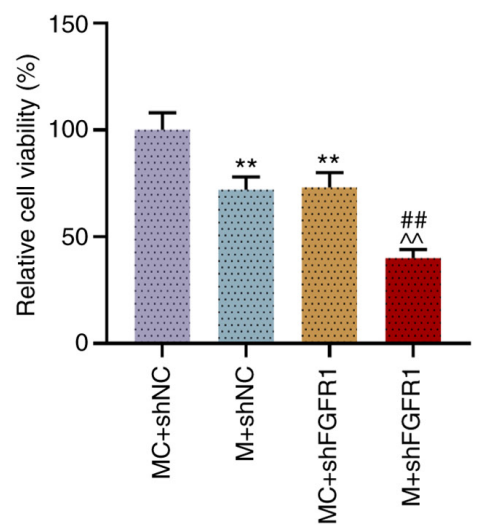

B

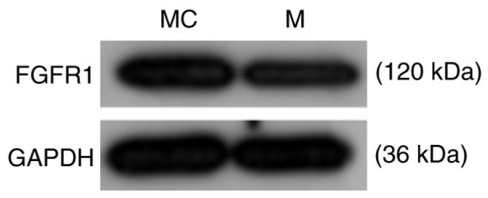

E

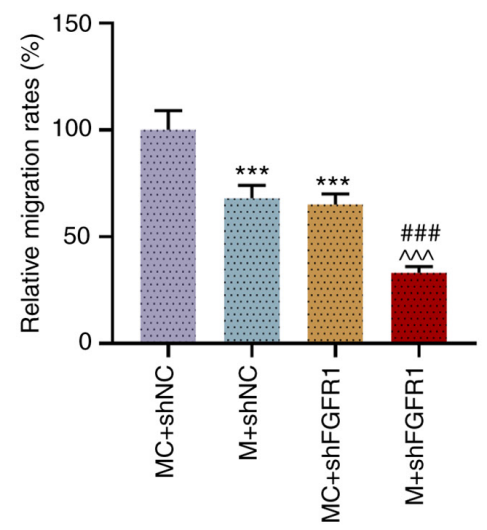

C

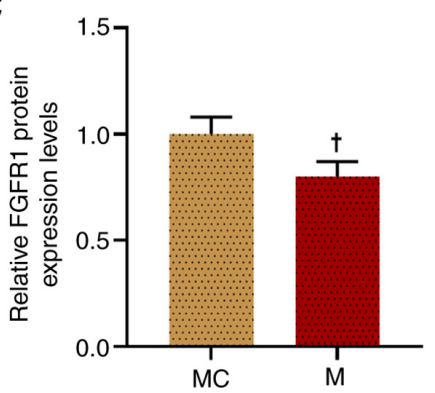

$\mathrm{F}$

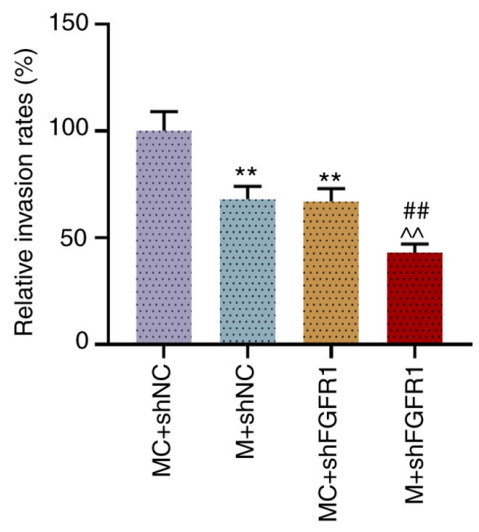

G
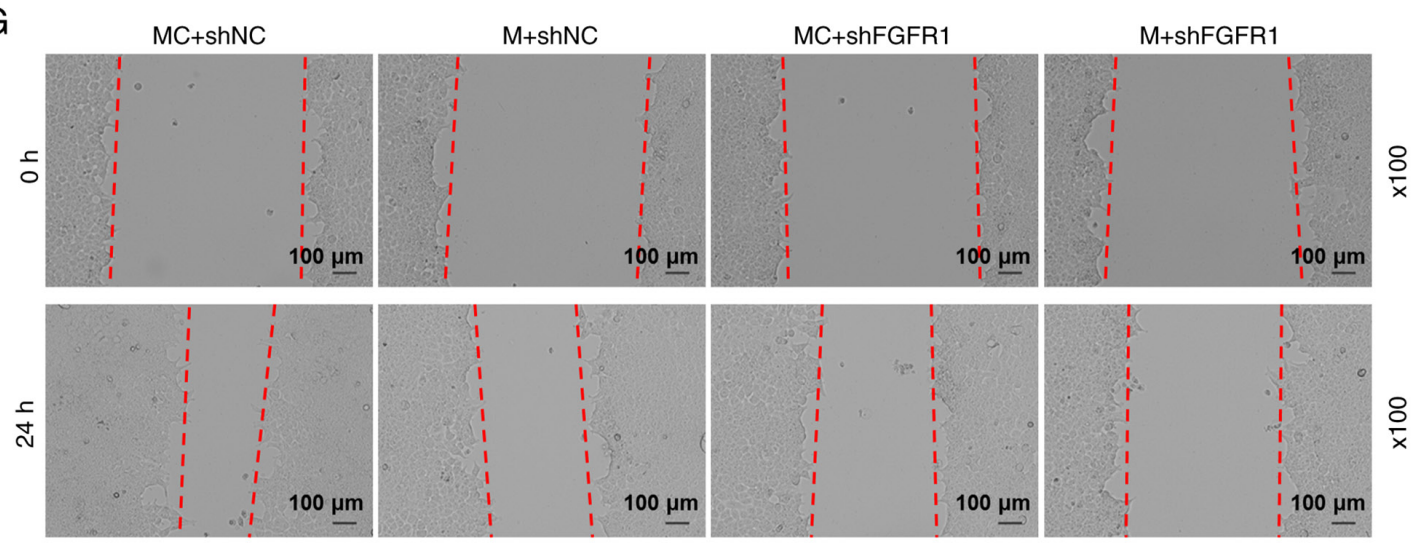

$\mathrm{H}$

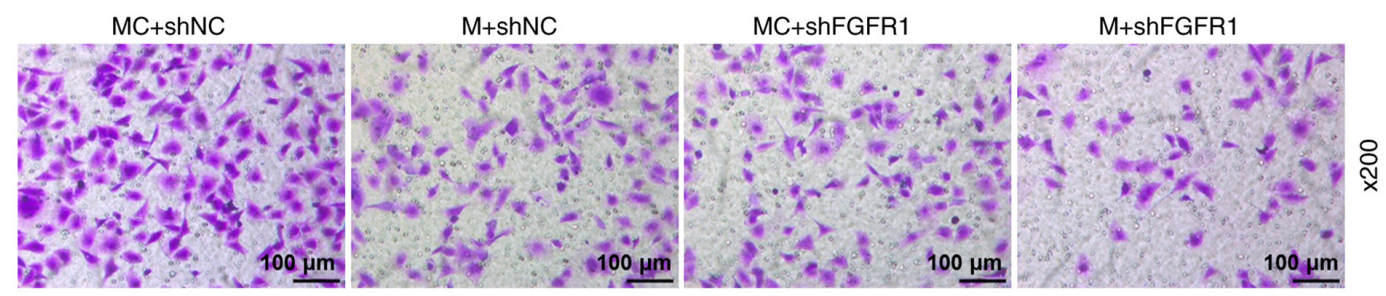

Figure 6. miR-133b can competitively bind with FGFR1 in TU212 cells, and miR-133b M and shFGFR1 inhibit cell viability, migration and invasion. (A) FGFR1 expression in transfected TU212 cells was examined via RT-qPCR, and GAPDH was used as a reference gene. (B and C) FGFR1 expression in transfected TU212 cells was examined via western blotting, and GAPDH was used as an internal loading control. (D) Viability of transfected TU212 cells was evaluated using a Cell Counting Kit-8 assay. (E and G) Migration of TU212 cell line after transfection was examined using a wound healing assay (magnification, x100). $\left(\mathrm{F}\right.$ and $\mathrm{H}$ ) Invasion of TU212 cell line after transfection was examined using a Transwell assay (magnification, $\mathrm{x} 200$ ). ${ }^{\dagger} \mathrm{P}<0.05,{ }^{\dagger \dagger} \mathrm{P}<0.001 \mathrm{vs}$. MC; ${ }^{* *} \mathrm{P}<0.01$, ${ }^{* * * *} \mathrm{P}<0.001$ vs. shNC $+\mathrm{MC} ;{ }^{\wedge \wedge} \mathrm{P}<0.01,{ }^{\wedge \wedge} \mathrm{P}<0.001$ vs. shNC $+\mathrm{M} ;{ }^{\# \#} \mathrm{P}<0.01,{ }^{\# \# \#} \mathrm{P}<0.001$ vs. shHCG18 + MC. RT-qPCR, reverse transcription-quantitative PCR; M, mimic; MC, mimic control; IC, inhibitor control; I, inhibitor; miR, microRNA; sh, short hairpin RNA; shNC, short hairpin negative control; FGFR1, fibroblast growth factor receptor 1 .

and $\mathrm{p}-\mathrm{AKT} / \mathrm{AKT}$ in transfected TU212 cells $(\mathrm{P}<0.01)$. Moreover, when cells were co-transfected with shFGFR1 and miR-133b M, the effects of shFGFR1 and miR-133b M on inhibiting Bcl-2 expression and the ratios of p-PI3K/PI3K and p-AKT/AKT and on promoting the expression levels of p53 and Bax were notably enhanced as compared with the $\mathrm{M}+\mathrm{shNC}$ and MC + shFGFR1 groups $(\mathrm{P}<0.01)$. Similarly, the results of RT-qPCR showed that shFGFR1 and miR-133b M promoted the expression levels of p53 and Bax yet inhibited that of Bcl-2, whereas they had no effect on the expression levels of PI3K and AKT $(\mathrm{P}<0.05)$. When the cells were co-transfected with miR-133b M and shFGFR1, the effects of shFGFR1 and miR-133b M on promoting the 

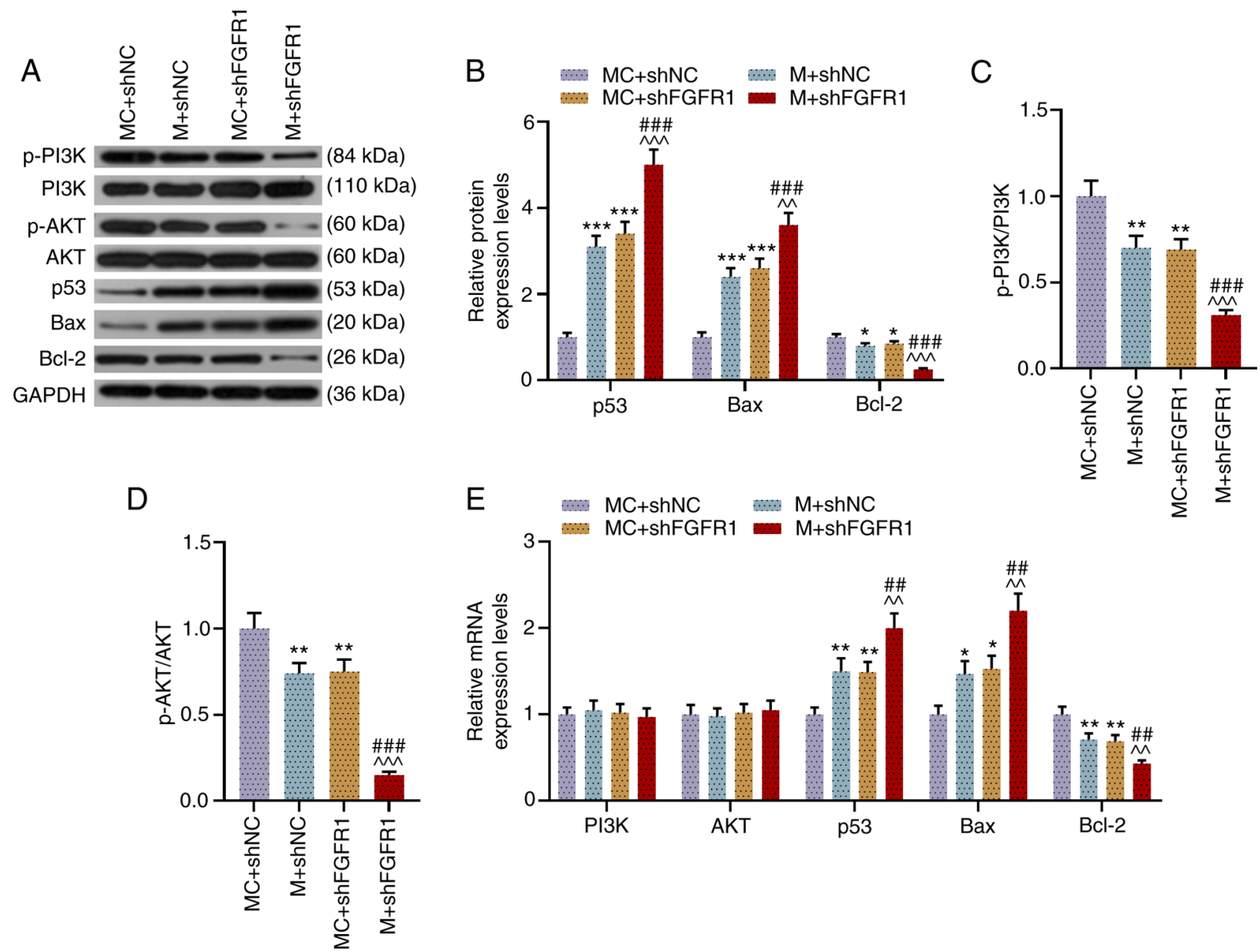

Figure 7. shFGFR 1 and miR-133b M promote the expression levels of $\mathrm{p} 53$ and Bax, while inhibiting those of Bcl-2, p-PI3K and p-AKT in TU212 cells. (A and B) Expression levels of p-PI3K, PI3K, p-AKT, AKT, p53, Bax and Bcl-2 in transfected TU212 cells were determined via western blotting, and GAPDH was used as an internal loading control. Ratios of (C) p-PI3K to PI3K and (D) p-AKT to AKT in transfected TU212 cells were analyzed using western blotting assays. (E) Expression levels of PI3K, AKT, p53, Bax and Bcl-2 in transfected TU212 cells were measured via reverse transcription-quantitative PCR, and GAPDH was used as a reference gene. ${ }^{\|} \mathrm{P}<0.05,{ }^{* * *} \mathrm{P}<0.01,{ }^{* * *} \mathrm{P}<0.001$ vs. shNC $+\mathrm{MC} ;{ }^{\wedge} \mathrm{P}<0.01,{ }^{\wedge \wedge} \mathrm{P}<0.001$ vs. shNC $+\mathrm{M} ;{ }^{\# \#} \mathrm{P}<0.01,{ }^{\# \#} \mathrm{P}<0.001$ vs. shHCG18 + MC. p-, phosphorylated; M, mimic; MC, mimic control; IC, inhibitor control; I, inhibitor; miR, microRNA; sh, short hairpin RNA; shNC, short hairpin negative control; FGFR1, fibroblast growth factor receptor 1.

expression levels of p53 and Bax, as well as inhibiting Bcl-2 expression, were significantly enhanced as compared with the $\mathrm{M}+$ shNC group and MC + shFGFR1 group $(\mathrm{P}<0.01 ;$ Fig. 7E) These data suggested that HCG18 may promote the viability, migration and invasion of LHSCC cells by regulating the FGFR1/miR-133b axis-mediated PI3K/AKT signaling pathway (Fig. 8).

\section{Discussion}

Although the exact etiology and mechanism of LHSCC remain to be further clarified, tumor metastasis and recurrence are the main reasons for the poor prognosis of LHSCC (3-5). Inhibition of cancer progression by repressing the migration and invasion of cancer cells is therefore an effective therapeutic option (20). Moreover, the migration and invasion of cancer cells are regulated by multiple genes (21).

lncRNAs play multifaceted roles in regulating gene expression in pathological processes, and dysregulation of lncRNAs is associated with a variety of pathological conditions, including

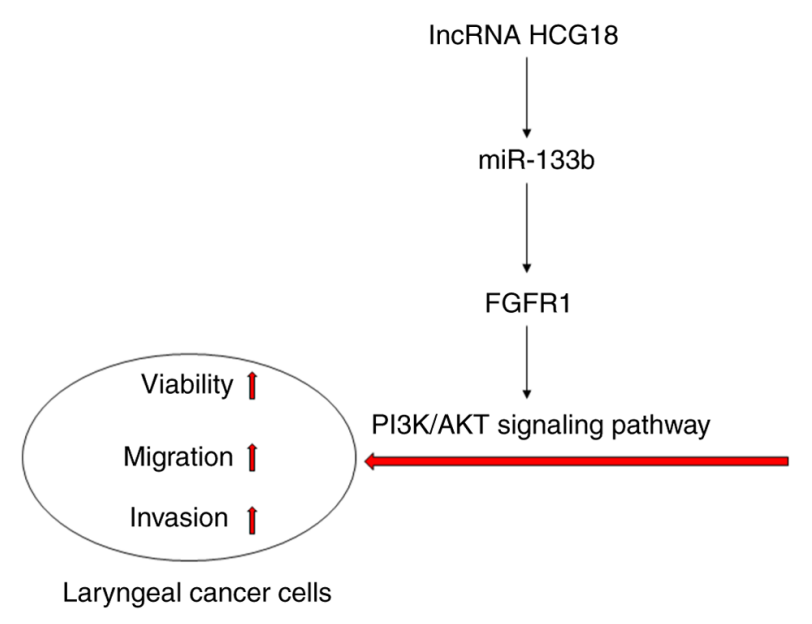

Figure 8. 1ncHCG18 is upregulated in LHSCC, and HCG18 could competitively bind with miR-133b. miR-133b is downregulated in LHSCC and can competitively bind with FGFR1. Downregulation of FGFR1 inhibits the viability, migration and invasion of LHSCC cells via the PI3K/AKT signaling pathway. miR, microRNA; FGFR1, fibroblast growth factor receptor 1; IncRNA, long non-coding RNA; HCG18, HLA complex group 18; LHSCC, laryngeal and hypopharyngeal squamous cell carcinoma. 
preeclampsia, cancer and cerebrovascular pathologies (22-24). It has been reported that the expression of HCG18 was promoted in gastric cancer tissues and colorectal cancer tissues, and knockdown the expression of HCG18 evidently decreased the proliferation, migration and invasion of cancer cells $(10,11)$. To the best of our knowledge, the present study demonstrated for the first time that HCG18 expression was increased in LHSCC tissues and promoted the progression of LHSCC, but its specific action mechanisms require further investigation.

Apart from lncRNAs, recent studies have shown that numerous miRNAs are differentially expressed during tumorigenesis (25). Previous studies have revealed that miR-133b was aberrantly expressed in several tumors, including colorectal cancer, esophageal squamous cell carcinoma and human tongue squamous cell carcinoma, and that lncRNAs are involved in cancer progression by targeting and regulating miRNAs expressions (16-19). The present study identified that miR-133b expression was decreased in LHSCC tissues, and that shHCG18 and miR-133b M inhibited the activity of LHSCC cells. In addition, several studies have reported that HCG18 acts as an oncogenic factor by regulating the expressions of miRNAs (13). To the best of our knowledge, the present study demonstrated for the first time that HCG18 could competitively bind with miR-133b in LHSCC cells, and that a miR-133b I promoted cell viability, migration, and invasion, while shHCG18 reversed the promotive effects of the miR-133b I. Thus, it was suggested that HCG18 promoted LHSCC progression by regulating miR-133b expression.

The interactions among lncRNA, miRNAs and mRNA, as well as complex molecular regulatory networks, have been evidenced in cancer (6). The FGFR1 gene is located on chromosome 8p12, and upregulation of FGFR1 expression is one of the most common genetic changes in tumors $(26,27)$. In recent years, the upregulation of FGFR1 has been found in breast cancer, ovarian cancer and tongue squamous cell carcinoma (28-30). Similarly, the amplification of FGFR1 may serve as an independent prognostic factor for disease-free survival in LHSCC (31). Related studies have shown that HCG18 promoted the progression of lung adenocarcinoma by regulating miR-34a-5p-mediated hyaluronan mediated motility receptor expression (12). The present study found that FGFR1 expression was increased in LHSCC, miR-133b could competitively bind with FGFR1 in LHSCC cells and shHCG18 enhanced the inhibitory effect of the miR-133b M. Collectively, these data suggested that HCG18 may facilitate LHSCC progression by upregulating FGFR1 via miR-133b. However, it remains necessary to identify the roles of HCG18, miR-133b and FGFR1 in LHSCC at the molecular level.

An increasing number of studies have shown that the PI3K/AKT and p53 signaling pathways have important roles in targeted therapy of human cancer types (32-34). In non-small cell lung cancer, miR-133b has the potential to be involved in the progression by regulating its target-mediated PI3K/AKT and p53 signaling pathways (35). In laryngeal cancer, lncRNA growth arrest-specific transcript 5 inhibits cancer cell invasion and proliferation via the PI3K/AKT/mTOR signaling pathway (36). Downregulation of sterol regulatory element binding transcription factor 1 inhibits the invasion by regulation of Bcl-2 and Bax and inhibition of the PI3K/AKT pathway in non-small-cell lung cancer (37). Both Bcl-2 and Bax belong to the Bcl-2 family, and Bcl-2 has the effect of inhibiting apoptosis, while Bax can promote apoptosis (38). p53 is one of the most important tumor-suppressor genes in human cancer (39). The present study identified that shHCG18 inhibited the expression levels of $\mathrm{Bcl}-2$, $\mathrm{p}-\mathrm{PI} 3 \mathrm{~K}$ and $\mathrm{p}-\mathrm{AKT}$, yet promoted those of p53 and Bax in LHSCC cells, while the miR-133b I reversed the effect of shHCG18; however, shFGFR1 further reversed the effect of the miR-133b I. The experimental results demonstrated that HCG18/miR-133b axis contributes LHSCC progression by regulating the FGFR1-mediated PI3K/AKT signaling pathway.

In conclusion, the present study identified that HCG18 expression was upregulated and that there was a relationship between HCG18 and miR-133b in LHSCC. The current results indicated that HCG18 facilitated LHSCC progression by upregulating FGFR1 via miR-133b, which may provide a new research direction and theoretical basis for targeted therapy of LHSCC.

\section{Acknowledgements}

Not applicable.

\section{Funding}

No funding was received.

\section{Availability of data and materials}

The datasets used and/or analyzed during the current study are available from the corresponding author on reasonable request.

\section{Authors' contributions}

HBP made substantial contributions to study conception and design. PJG performed data acquisition, data analysis and interpretation. HBP drafted the article and critically revised it for important intellectual content. Both authors read and approved the final manuscript, as well as agreed to be accountable for all aspects of the work in ensuring that questions related to the accuracy or integrity of the work are appropriately investigated and resolved. HBP and PJG confirmed the authenticity of all the raw data.

\section{Ethics approval and consent to participate}

This study was discussed and approved by the Zhongshan Hospital of Traditional Chinese Medicine Affiliated to Guangzhou University of Chinese Medicine Ethics Committee (approval no. JN2020020208), and all tissue samples were confirmed to be LHSCC. Written informed consent was obtained from the participating patients. All procedures performed in studies involving human participants were in accordance with the ethical standards of the institutional and/or national research committee and with the 1964 Helsinki declaration and its later amendments or comparable ethical standards.

\section{Patient consent for publication}

Not applicable. 


\section{Competing interests}

The authors declare that they have no competing interests.

\section{References}

1. Song L, Zhang S, Yu S, Ma F, Wang B, Zhang C, Sun J, Mao X and Wei L: Cellular heterogeneity landscape in laryngeal squamous cell carcinoma. Int J Cancer 147: 2879-2890, 2020.

2. Abdeyrim A, He S, Zhang Y, Mamtali G, Asla A, Yusup M and Liu J: Prognostic value of lymph node ratio in laryngeal and hypopharyngeal squamous cell carcinoma: A systematic review and meta-analysis. J Otolaryngol Head Neck Surg 49: $31,2020$.

3. Colevas AD, Yom SS, Pfister DG, Spencer S, Adelstein D, Adkins D, Brizel DM, Burtness B, Busse PM, Caudell JJ, et al: NCCN guidelines insights: Head and neck cancers, Version 1.2018. J Natl Compr Canc Netw 16: 479-490, 2018.

4. Dietz A, Wiegand S, Kuhnt T and Wichmann G: Laryngeal preservation approaches: Considerations for new selection criteria based on the DeLOS-II trial. Front Oncol 9: 625, 2019.

5. Yang L, Luo D, Yi J, Li L, Zhao Y, Lin M, Guo W, Hu L and Zhou C: Therapy effects of advanced hypopharyngeal and laryngeal squamous cell carcinoma: Evaluated using dual-energy CT quantitative parameters. Sci Rep 8: 9064 2018.

6. Tang XJ, Wang W and Hann SS: Interactions among lncRNAs, miRNAs and mRNA in colorectal cancer. Biochimie 163 . $58-72,2019$

7. Zhang Y and Tang L: The application of lncRNAs in cancer treatment and diagnosis. Recent Pat Anticancer Drug Discov 13: 292-301, 2018

8. Nandwani A, Rathore S and Datta M: IncRNAs in cancer: Regulatory and therapeutic implications. Cancer Lett 501: 162-171, 2021.

9. Taniue $\mathrm{K}$ and Akimitsu $\mathrm{N}$ : The functions and unique features of lncRNAs in cancer development and tumorigenesis. Int J Mol Sci 22: 632, 2021.

10. Ma P, Li L, Liu F and Zhao Q: HNF1A-induced lncRNA HCG18 facilitates gastric cancer progression by upregulating DNAJB12 via miR-152-3p. Onco Targets Ther 13: 7641-7652, 2020.

11. Li S, Wu T, Zhang D, Sun X and Zhang X: The long non-coding RNA HCG18 promotes the growth and invasion of colorectal cancer cells through sponging miR-1271 and upregulating MTDH/Wnt/ $\beta$-catenin. Clin Exp Pharmacol Physiol 47: 703-712, 2020

12. Li W, Pan T, Jiang W and Zhao H: HCG18/miR-34a-5p/HMMR axis accelerates the progression of lung adenocarcinoma. Biomed Pharmacother 129: 110217, 2020.

13. Li L, Ma TT, Ma YH and Jiang YF: IncRNA HCG18 contributes to nasopharyngeal carcinoma development by modulating miR-140/CCND1 and Hedgehog signaling pathway. Eur Rev Med Pharmacol Sci 23: 10387-10399, 2019.

14. Testa U, Pelosi E, Castelli G and Labbaye C: miR-146 and miR-155: Two key modulators of immune response and tumor development. Noncoding RNA 3: 22, 2017.

15. Xu Z, Huang B, Zhang Q, He X, Wei H and Zhang D: NOTCH1 regulates the proliferation and migration of bladder cancer cells by cooperating with long non-coding RNA HCG18 and microRNA-34c-5p. J Cell Biochem 120: 6596-6604, 2019.

16. Georgantas RW, Streicher K, Greenberg SA, Greenlees LM, Zhu W, Brohawn PZ, Higgs BW, Czapiga M, Morehouse CA, Amato A, et al: Inhibition of myogenic microRNAs 1, 133, and 206 by inflammatory cytokines links inflammation and muscle degeneration in adult inflammatory myopathies. Arthritis Rheumatol 66: 1022-1033, 2014.

17. Lv L, Li Q, Chen S, Zhang X, Tao X, Tang X, Wang S, Che G, $\mathrm{Yu}$ Y and He L: miR-133b suppresses colorectal cancer cell stemness and chemoresistance by targeting methyltransferase DOT1L. Exp Cell Res 385: 111597, 2019.

18. Zeng W, Zhu JF, Liu JY, Li YL, Dong X, Huang H and Shan L: miR-133b inhibits cell proliferation, migration and invasion of esophageal squamous cell carcinoma by targeting EGFR. Biomed Pharmacother 111: 476-484, 2019.

19. Zhang K, Zhou H, Yan B and Cao X: TUG1/miR-133b/CXCR4 axis regulates cisplatin resistance in human tongue squamous cell carcinoma. Cancer Cell Int 20: 148, 2020.
20. Xia L, Li S, Liu Y, Huang Y, Ni B, Wan L, Mei H, Li X, Cai Z and $\mathrm{Li} Z$ : NDNF inhibits the migration and invasion of human renal cancer cells through epithelial-mesenchymal transition. Oncol Lett 17: 2969-2975, 2019.

21. Bian Q: Circular RNA PVT1 promotes the invasion and epithelial-mesenchymal transition of breast cancer cells through serving as a competing endogenous RNA for miR-204-5p. Onco Targets Ther 12: 11817-11826, 2019.

22. Song X, Luo X, Gao Q, Wang Y, Gao Q and Long W: Dysregulation of lncRNAs in placenta and pathogenesis of preeclampsia. Curr Drug Targets 18: 1165-1170, 2017.

23. Lou W, Ding B, Zhong G, Du C, Fan W and Fu P: Dysregulation of pseudogene/lncRNA-hsa-miR-363-3p-SPOCK2 pathway fuels stage progression of ovarian cancer. Aging (Albany NY) 11: $11416-11439,2019$

24. Zhang X, Tang X, Liu K, Hamblin MH and Yin KJ: Long noncoding RNA malat1 regulates cerebrovascular pathologies in ischemic stroke. J Neurosci 37: 1797-1806, 2017.

25. Mamoori A, Gopalan V and Lam AK: Role of miR-193a in cancer: Complexity and factors control the pattern of its expression. Curr Cancer Drug Targets 18: 618-628, 2018.

26. Malchers F, Ercanoglu M, Schütte D, Castiglione R, Tischler V, Michels S, Dahmen I, Brägelmann J, Menon R, Heuckmann JM, et al: Mechanisms of primary drug resistance in FGFR1-amplified lung cancer. Clin Cancer Res 23: 5527-5536, 2017.

27. Haq F, Sung YN, Park I, Kayani MA, Yousuf F, Hong SM and Ahn SM: FGFR1 expression defines clinically distinct subtypes in pancreatic cancer. J Transl Med 16: 374, 2018

28. Chen S, Qiu Y, Guo P, Pu T, Feng Y and Bu H: FGFR1 and HER1 or HER2 co-amplification in breast cancer indicate poor prognosis. Oncol Lett 15: 8206-8214, 2018.

29. Uusi-Kerttula H, Legut M, Davies J, Jones R, Hudson E, Hanna L, Stanton RJ, Chester JD and Parker AL: Incorporation of peptides targeting EGFR and FGFR1 into the adenoviral fiber knob domain and their evaluation as targeted cancer therapies. Hum Gene Ther 26: 320-329, 2015.

30. Jiao J, Zhao X, Liang Y, Tang D and Pan C: FGF1-FGFR1 axis promotes tongue squamous cell carcinoma (TSCC) metastasis through epithelial-mesenchymal transition (EMT). Biochem Biophys Res Commun 466: 327-332, 2015.

31. Kim EK, Cho YA, Koh YW, Shin HA, Cho BC and Yoon SO: Prognostic implications of Fibroblast growth factor receptor 1 (FGFR1) gene amplification and protein overexpression in hypopharyngeal and laryngeal squamous cell carcinoma. BMC Cancer 20: 348, 2020.

32. Murugan AK: Special issue: PI3K/Akt signaling in human cancer. Semin Cancer Biol 59: 1-2, 2019.

33. Narayanankutty A: PI3K/Akt/mTOR pathway as a therapeutic target for colorectal cancer: A review of preclinical and clinical evidence. Curr Drug Targets 20: 1217-1226, 2019.

34. Khan H, Reale M, Ullah H, Sureda A, Tejada S, Wang Y, Zhang ZJ and Xiao J: Anti-cancer effects of polyphenols via targeting p53 signaling pathway: Updates and future directions. Biotechnol Adv 38: 107385, 2020.

35. Chen GY and Ruan L: Downregulation Of microRNA-133b and its clinical value in non-small cell lung cancer. Onco Targets Ther 12: 9421-9434, 2019.

36. Liu W, Zhan J, Zhong R, Li R, Sheng X, Xu M, Lu Z and Zhang S: Upregulation of long noncoding RNA_GAS5 suppresses cell proliferation and metastasis in laryngeal cancer via regulating PI3K/AKT/mTOR signaling pathway. Technol Cancer Res Treat 20: 1533033821990074, 2021.

37. Zhang B, Wu J, Guo P, Wang Y, Fang Z, Tian J, Yu Y, Teng W, Luo Y and Li Y: Down-regulation of SREBP via PI3K/AKT/mTOR pathway inhibits the proliferation and invasion of non-small-cell lung cancer cells. Onco Targets Ther 13: 8951-8961, 2020

38. Bumbat M, Wang M, Liang W, Ye P, Sun W and Liu B: Effects of $\mathrm{Me} 2 \mathrm{SO}$ and trehalose on the cell viability, proliferation, and Bcl-2 family gene (BCL-2, BAX, and BAD) expression in cryopreserved human breast cancer cells. Biopreserv Biobank 18: 33-40, 2020.

39. Hong B, van den Heuvel AP, Prabhu VV, Zhang S and El-Deiry WS: Targeting tumor suppressor p53 for cancer therapy: Strategies, challenges and opportunities. Curr Drug Targets 15: 80-89, 2014. 